\title{
THE ATMOSPHERES OF MARS AND VENUS
}

\author{
ANDREW P. INGERSOLL \\ Division of Geological and Planetary Sciences, California \\ Institute of Technology, Pasadena, California
}

Conway B. Leovy

Atmospheric Sciences and Geophysics, University of Washington, Seattle, Washington

\section{INTRODUCTION}

Of all the planets which may exist in the Universe, only nine have been studied by man. As a result, one cannot classify planets with the same confidence that one has in classifying stars; there is no theory of planetary evolution comparable in development to the theory of stellar evolution. Nevertheless, many of the goals of planetary science and stellar astronomy are the same: to classify objects according to their most fundamental properties in order to understand their present physical state and their evolution. From this point of view, the terrestrial planets comprise a group which can usefully be considered together. By comparing the similarities and differences between them, we may hope to gain insight into the evolution of the entire group.

Perhaps the most fundamental basis for identifying the terrestrial planets as a group is the similarity of their densities. The mean densities of Mercury, Venus, Earth, and Mars are 5.4, 5.1, 5.5, and $4.0 \mathrm{~g} / \mathrm{cm}^{3}$, respectively, and their masses are $0.054,0.815,1.000$, and 0.108 in units of the Earth's mass. From these data, it is believed that the terrestrial planets consist mainly of the cosmically abundant metals $\mathrm{Fe}, \mathrm{Si}, \mathrm{Mg}, \mathrm{Ca}, \mathrm{Al}$, and their oxides. Their atmospheres consist mainly of the cosmically abundant elements $\mathrm{H}, \mathrm{C}, \mathrm{O}, \mathrm{N}$, in compounds such as $\mathrm{CO}_{2}, \mathrm{H}_{2} \mathrm{O}, \mathrm{N}_{2}, \mathrm{O}_{2}$. Thus the terrestrial planets are further distinguished by the high degree of oxidation of their atmospheres. It is generally assumed that the compounds $\mathrm{CO}_{2}, \mathrm{H}_{2} \mathrm{O}$, etc, observed at the surfaces of the terrestrial planets, represent the volatile fraction released from the interiors after planetary accretion.

This review will focus on the atmospheres of Mars and Venus. These planets' atmospheres consist mainly of $\mathrm{CO}_{2}$, and so it is convenient to consider them together. In contrast, Mercury appears to have no atmosphere. This may be due either to a different internal history or to an inability to hold an atmosphere. The Earth's atmosphere is beyond the scope of this review, but we shall compare the abundances of $\mathrm{CO}_{2}, \mathrm{H}_{2} \mathrm{O}, \mathrm{N}_{2}$, etc, on the Earth, 
Mars, and Venus in order to better understand the terrestrial planets as a group.

Several published conference proceedings (Brancazio \& Cameron 1964, Brandt \& McElroy 1968, Jastrow \& Rasool 1969, Sagan, Owen \& Smith 1971), and a number of excellent review articles (Sagan \& Kellogg 1963, Jastrow 1968, Hunten \& Goody 1969, Goody 1969, Eshleman 1970), dealing with planetary atmospheres, have appeared in recent years. Progress in this field has been so rapid that a further survey of the present state of knowledge of the atmospheres of Mars and Venus seems warranted. In this review, we shall compare the compositions, thermal structures, and dynamics of the lower and upper atmospheres of Mars and Venus, and shall consider some of the problems of their evolution. The remainder of the Introduction consists of brief reviews of attempts to detect an atmosphere on Mercury, and of the abundances of volatile constituents of the Earth's atmosphere and oceans.

Observations of Mercury. - The search for an atmosphere on Mercury has thus far yielded negative results. The published upper limit to the $\mathrm{CO}_{2}$ abundance is $0.58 \mathrm{~m}$-atm, or $0.04 \mathrm{mb}$ surface pressure (Belton, Hunten \& McElroy 1967, Bergstralh, Gray \& Smith 1967). An upper limit to the $\mathrm{H}_{2} \mathrm{O}$ abundance is $30 \mu$ precipitable water (equivalent to a layer of liquid water 30 $\mu$ thick), or $10^{-3} \mathrm{mb}$ surface pressure (Spinrad, Field \& Hodge 1965). The search for evidence of other gases in Mercury spectra has also yielded negative results.

Gases whose spectra are unobservable from the Earth can be detected in other ways. An upper limit to total pressure at the surface of Mercury of 0.4 $\mathrm{mb}$ is inferred from comparison of polarization curves for Mercury, the Moon, and powdered silicate samples observed in the laboratory (O'Leary \& Rea 1967, Ingersoll 1971). The low value of surface thermal conductivity inferred from infrared and radio temperature measurements implies surface pressures less than about $0.1 \mathrm{mb}$ (Morrison \& Sagan 1967, Murdock \& Ney 1970, Morrison 1970); for $P>0.1 \mathrm{mb}$, heat transport by gas within the soil material would raise the thermal conductivity above the observed value. A more stringent, but a speculative upper limit of $10^{-5} \mathrm{mb}$ for the surface pressure follows from the assumption that the similarity between the photometric functions of Mercury and the Moon is a consequence of bombardment by the solar wind (Sagan 1966, O'Leary \& Rea 1967). In any case, we adopt the prevailing view that Mercury, like the Moon, has essentially no atmosphere.

Volatiles on the Earth.-The Earth's atmosphere is about $75 \% \mathrm{~N}_{2}$ and $23 \% \mathrm{O}_{2}$ by volume, with smaller amounts of $\mathrm{H}_{2} \mathrm{O}, \mathrm{CO}_{2}$, and other gases. However, a complete inventory of the Earth's volatiles includes the water in the Earth's oceans and the $\mathrm{CO}_{2}$ buried in sedimentary rocks (Rubey 1951). The mass of the oceans averaged over the surface of the Earth is $300 \mathrm{~kg} /$ 
$\mathrm{cm}^{2}$, corresponding to a mean pressure at the bottom of the oceans of 300 atm. An additional $150 \mathrm{~kg} / \mathrm{cm}^{2}$ of water is thought to be buried in sedimentary rocks (Ronov \& Yaroshevsky 1967). The amount of $\mathrm{CO}_{2}$ in sedimentary rocks (as carbonate and organic carbon) is about $40 \mathrm{~kg} / \mathrm{cm}^{2}$, and an equal amount in igneous rocks may represent recycled sedimentary $\mathrm{CO}_{2}$ (Ronov \& Yaroshevsky 1967). It is believed that carbonate deposition has taken place continuously for most of the Earth's lifetime, and that the volatiles buried in this way represent part of the volatile fraction which has been released from the Earth's interior (Rubey 1951).

There is substantial evidence that these volatiles were released from the interior after the Earth formed (Brown 1952). In the first place, the low abundance of rare gases suggests that the Earth never had a primitive atmosphere of roughly solar composition, or that the primitive atmosphere was lost. Second, the fact that the volatile compounds $\mathrm{H}_{2} \mathrm{O}, \mathrm{CO}_{2}, \mathrm{~N}_{2}, \mathrm{O}_{2}$, etc are relatively more abundant than the rare gases indicates that these compounds were retained chemically while the rare gases were being lost. Thus the constituents of the present atmosphere and oceans of the Earth have been released from the interior. One unsolved problem of planetary science is whether the differences we find among the terrestrial planets' atmospheres are due to differences in their internal histories or to differences in conditions which have prevailed at their surfaces.

\section{Atmospheric Abundances}

Carbon dioxide.-The only direct sampling of a planetary atmosphere other than the Earth's was carried out on the Soviet entry probes Venera 4, 5, and 6 (Vinogradov, Surkov \& Florensky 1968, Avduevsky, Marov \& Rozhdestvensky 1970). Data on the composition of the Venus atmosphere were obtained at two levels, $P=0.6$ and $2.0 \mathrm{~atm}$, respectively, where $P$ is total atmospheric pressure. The $\mathrm{CO}_{2}$ gas analyzer indicated that the molar fraction of $\mathrm{CO}_{2}$ is in the range $93-97 \%$.

Estimates of the total amount of $\mathrm{CO}_{2}$ in the atmosphere are obtained indirectly. The Mariner 5 radio occultation experiments give atmospheric refractivity above the $P=7 \mathrm{~atm}$ level as a function of distance to the center of the planet (Kliore \& Cain 1968, Eshleman et al 1968). Pressure and temperature profiles above this level are obtained with the aid of the hydrostatic relation. Surface pressure is estimated by extrapolating to the surface, using the value of the radius of the solid planet obtained from ground-based radar data (Ash et al 1968, Melbourne, Muhleman \& O'Handley 1968). The estimated value of the surface pressure is in the range 70-120 atm, corresponding to $70-120 \mathrm{~kg} / \mathrm{cm}^{2}$ of $\mathrm{CO}_{2}$ averaged over the surface of Venus. This estimate is in accord with estimates based on the observed opacity of the atmosphere from ground-based radar data, if it is assumed that $\mathrm{CO}_{2}$ is the principal absorber of radio waves (Wood, Watson \& Pollack 1968, Muhleman 1969, Slade \& Shapiro 1970).

The $\mathrm{CO}_{2}$ abundance on Mars has been measured spectroscopically. The 
Mars atmosphere, unlike that of Venus, is optically thin, and therefore the spectrum of sunlight reflected by the surface of Mars contains information about the total abundance of $\mathrm{CO}_{2}$. This abundance is in the range 60-85 $\mathrm{m}$-atm, corresponding to a partial pressure 4.5-6.5 mb (Kaplan, Munch \& Spinrad 1964, Giver et al 1968, Young 1969, Carleton et al 1969). From these studies it is also possible to determine the total pressure from the broadening of spectral lines, and it appears that $\mathrm{CO}_{2}$ is the major constituent of the Mars atmosphere as well. Total pressure is also determined from the surface refractivity obtained during the Mariner 4, 6, and 7 flybys (Kliore et al 1969a, Rasool et al 1970), and these results fall in the range 4.9-7.6 mb. Here the spread of values is real, and is probably due to topographic differences at the entrance and exit points for the different spacecraft (Pettengill et al 1969, Goldstein et al 1970). It has been established that the polar caps contain solid $\mathrm{CO}_{2}$ (Leighton \& Murray 1966, Herr \& Pimentel 1969, Neugebauer et al 1969), so the total amount of $\mathrm{CO}_{2}$ on Mars may be much greater than that observed in the atmosphere.

The $\mathrm{CO}_{2}$ abundances for Venus, Mars, and the Earth are summarized in Table 1. For the Earth, the atmospheric abundance and the total abundance, including all forms of $\mathrm{CO}_{2}$ known to have passed through the atmosphere, are given separately. For Venus and Mars, the total abundance is largely unknown. The Mars polar caps may contain large amounts of solid $\mathrm{CO}_{2}$, and it is possible that the Venus surface is covered by carbonate deposits which contain an appreciable fraction of that planet's $\mathrm{CO}_{2}$ (Mueller 1964, Lewis 1968). Clearly, $\mathrm{CO}_{2}$ is an abundant volatile compound at the surfaces of Venus, Earth, and Mars, but it is not yet possible to compare the total amounts of $\mathrm{CO}_{2}$ at or near the surfaces of these planets.

Water.-The Venera entry probes detected water on Venus by indicating an increase in electrical conductivity of $\mathrm{P}_{2} \mathrm{O}_{5}$ when it was exposed to the atmosphere. At the two levels $P=0.6$ and $P=2.0 \mathrm{~atm}$, the molar fraction of

TABLE 1. Abundance of volatiles ${ }^{a}$

\begin{tabular}{l|llll}
\hline \hline Volatile & $\begin{array}{c}\text { Earth } \\
\text { atmosphere }\end{array}$ & $\begin{array}{c}\text { Earth } \\
\text { total }\end{array}$ & $\begin{array}{c}\text { Venus } \\
\text { atmosphere }\end{array}$ & $\begin{array}{c}\text { Mars } \\
\text { atmosphere }\end{array}$ \\
\cline { 1 - 5 } $\mathrm{CO}_{2}$ & $0.5 \times 10^{-3}$ & $70 \pm 30$ & $95 \pm 25$ & $(1.4 \pm 0.2) \times 10^{-2}$ \\
$\mathrm{H}_{2} \mathrm{O}$ & $(1-10) \times 10^{-3}$ & $375 \pm 75$ & $10^{-2 \pm}$ & $(0.5-2.5) \times 10^{-6}$ \\
$\mathrm{O}_{2}$ & 0.23 & $\sim 0.23$ & $<6 \times 10^{-3}$ & $<2.5 \times 10^{-5}$ \\
$\mathrm{~N}_{2}$ & 0.75 & $\sim 0.75$ & $<5$ & $<0.8 \times 10^{-3}$ \\
$\mathrm{Ar}$ & $1.3 \times 10^{-2}$ & $\sim 1.3 \times 10^{-2}$ & $<5$ & $<0.3 \times 10^{-2}$ \\
$\mathrm{CO}$ & $(1-10) \times 10^{-7}$ & $\sim 10^{-6}$ & $3 \times 10^{-8}$ & $0.7 \times 10^{-5}$ \\
$\mathrm{Cl}$ & - & 5.7 & $5 \times 10^{-5}$ & - \\
$\mathrm{F}$ & - & $0.3 \times 10^{-8}$ & $2 \times 10^{-7}$ & - \\
\hline
\end{tabular}

- Units: $\mathrm{kg} / \mathrm{cm}^{2}$. 
water was found to be in the range $0.1-1.0 \%$ (Vinogradov, Surkov \& Florensky 1968, Avduevsky, Marov \& Rozhdestvensky 1970). However, Lewis (1969) has argued that the change in electrical conductivity is due to the presence of concentrated aqueous solutions of $\mathrm{HCl}$ in the Venus clouds, and that the mole fraction of water in the atmosphere is only $10^{-4}$. Kuiper (1969b) has argued that the change in conductivity may be due to the presence of partially hydrated $\mathrm{FeCl}_{2}$ in the clouds, and that the mole fraction of water is $10^{-6}$. There is a regrettable lack of agreement on the interpretation of these important measurements.

Pollack \& Morrison (1970) have pointed out that the anomalously low brightness temperatures observed for Venus in the vicinity of the $1.35 \mathrm{~cm}$ water vapor line can be accounted for if the water vapor mixing ratio of the lower atmosphere is in the range $(0.3-1.0) \times 10^{-2}$ (Figure 1). Others (Avduevsky et al 1970, Ohring 1969, Pollack 1969) observe that this amount of water is sufficient to supply the high infrared opacity needed to maintain the high surface temperatures of Venus. However, neither of these arguments positively identifies water as the unknown absorber.

Spectroscopic studies of sunlight reflected in the Venus atmosphere imply

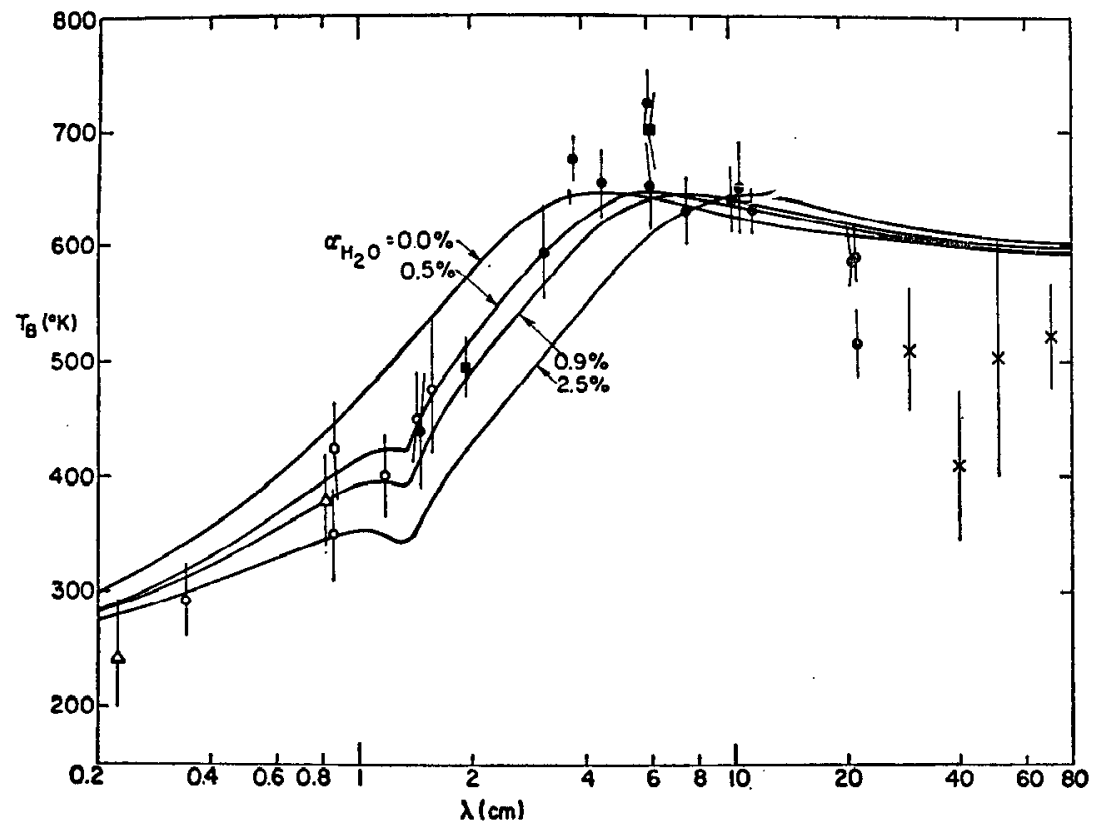

FIGURE 1. The average brightness temperature of Venus at wavelengths from 2 $\mathrm{mm}$ to $70 \mathrm{~cm}$. The points are from Dickel (1967) and Pollack \& Morrison (1970), and represent the work of many observers. The curves were computed by Pollack \& Morrison (1970) assuming an adiabatic lower atmosphere, and are labeled by the assumed percentage molar abundance of water vapor. 
water vapor mixing ratios $\leqslant 10^{-4}$ (Dollfus 1963, Bottema, Plummer \& Strong 1965, Belton \& Hunten 1966, Spinrad \& Shawl 1966, Belton, Hunten \& Goody 1968), that is, $<100 \mu$ precipitable water above the level of spectral line formation (Figure 2). Studies at longer wavelengths in the stronger bands of water vapor indicate even less water, e.g. $<20 \mu$ (Connes et al 1967) and $\sim 5 \mu$ (Kuiper 1969a) precipitable water.

Schorn et al (1969) have detected water in a number of lines near $8200 \AA$, and they report that the amount of water varies from day to day between zero and 30-40 $\mu$. Thus the spectroscopic studies can only be reconciled with the Venera results if the former refer to a higher, colder level in the atmosphere, where water vapor is effectively condensed out. The question is therefore whether ice clouds are consistent with the spectroscopic observations, and this will be considered in our general discussion of clouds. The debate over the nature of the Venus clouds is intimately tied to the question of the abundance of water on Venus.

Water has also been detected spectroscopically on Mars (Kaplan, Munch $\&$ Spinrad 1964). The amount of precipitable water in a vertical column above the surface varies with the seasons from $<5$ to $\sim 25 \mu$, which indicates that the mean relative humidity of the Mars atmosphere is as much as $50 \%$ (Schorn, Farmer \& Little 1969). Liquid water at the surface of Mars is deemed highly unlikely by Ingersoll (1970a). However, there is some spectroscopic evidence that the polar caps contain water ice (Kieffer 1970a,b), and it is possible that large amounts of water are present either as permafrost

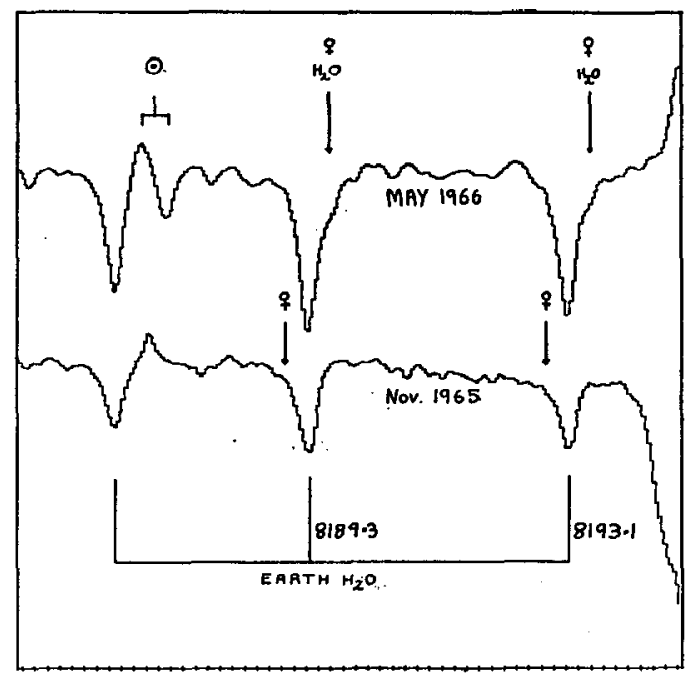

FIGURE 2. Ratio of Venus and Sun spectra near the 8189 and $8193 \AA$ lines of water vapor, showing weak Doppler-shifted Venus lines on the wings of strong unshifted telluric lines. From Belton \& Hunten (1966); copyright, the University of Chicago. 
(Leighton \& Murray 1966) or as water of hydration in surface minerals (Pollack et al 1970). Thus, from atmospheric abundances alone, it is impossible to estimate the total abundance of water on the surface of Mars.

Water abundances are also summarized in Table 1. There are no oceans or ice caps on the surface of Venus (Gale \& Sinclair 1969), but it is remotely possible that large amounts of water are bound chemically at the surface. It is more likely that all the water is in the atmosphere, in which case Venus has no more than $10^{-3}$ of the amount of water that the Earth has.

Other gases.-The Venera gas analyzer measured the partial pressure of gases other than $\mathrm{CO}_{2}$ at the $P=0.6$ and 2.0 atm level on Venus. From this, the experimenters concluded that the mole fraction of $\mathrm{N}_{2}$ and other inert gases is in the range 2-5\% (Avduevsky, Marov \& Rozhdestvensky 1970). These figures, taken at face value, are significant. They imply that the partial pressure of $\mathrm{N}_{2}$ at the surface of Venus may be as great as $5 \mathrm{~atm}$, and that the partial pressure of $\mathrm{N}_{2}$ and other inert gases is no less than $2 \mathrm{~atm}$.

Other gases that have been positively identified on Venus are $\mathrm{HCl}$ (Figure 3), HF, and CO (Connes et al 1967, 1968). Their molar abundances relative to $\mathrm{CO}_{2}$ are $6 \times 10^{-7}, 5 \times 10^{-9}$, and $4.5 \times 10^{-5}$, respectively. These figures refer to conditions in the clouds, and presumably to conditions in the lower atmosphere as well. It is interesting to compare the $\mathrm{CO}$ abundance with the $\mathrm{O}_{2}$ upper limit obtained by Belton \& Hunten $(1968,1969 \mathrm{a})$. For the mole fraction of $\mathrm{O}_{2}$ relative to $\mathrm{CO}_{2}$, they obtained $\mathrm{O}_{2} / \mathrm{CO}_{2}<(2$ or 8$) \times 10^{-5}$, the value depending on whether absorption takes place within or above the clouds, respectively. Thus the elemental abundance ratio of oxygen to carbon in the Venus atmosphere may be less than 2 by a small but significant amount. The amount of $\mathrm{CO}$ above the level of line formation is about 13 cm-atm, approximately 50-100 times that in the Earth's atmosphere.

Values of the total surface pressure on Mars inferred from the broadening of spectral lines fall in the range 5-7 mb (Kaplan, Connes \& Connes 1969, Young 1969), in agreement with the Mariner occultation results (Rasool et al 1970). Since these values are not significantly greater than the $\mathrm{CO}_{2}$ partial pressure, the partial pressure of other gases including $\mathrm{N}_{2}$ is less than 1-2 mb on Mars.

Still more stringent upper limits on $\mathrm{N}_{2}$ were obtained with the Mariner 6 and 7 ultraviolet spectrometer (Barth et al 1969). The spectrum of the Mars upper atmosphere from $1100-4300 \AA$ showed emission features of $\mathrm{CO}, \mathrm{O}$, and $\mathrm{CO}_{2}{ }^{+}$, but no evidence of $\mathrm{N}_{2}$ (Figure 4 ). The maximum mole fraction of $\mathrm{N}_{2}$ relative to $\mathrm{CO}_{2}$ at the level of observation $(200 \mathrm{~km})$ was estimated to be about $5 \%$ (Dalgarno \& McElroy 1970). However, the ratio of $\mathrm{N}_{2}$ to $\mathrm{CO}_{2}$ is likely to increase with height as a result of diffusive separation of the lighter gas in the upper atmosphere, so the actual mole fraction of $\mathrm{N}_{2}$ in the lower atmosphere is probably less than $5 \%$. These results imply that the partial pressure of $\mathrm{N}_{2}$ at the surface is less than $0.3 \mathrm{mb}$.

The only gas other than $\mathrm{CO}_{2}$ and $\mathrm{H}_{2} \mathrm{O}$ which has been positively identified 


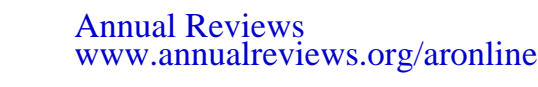

154

INGERSOLL \& LEOVY

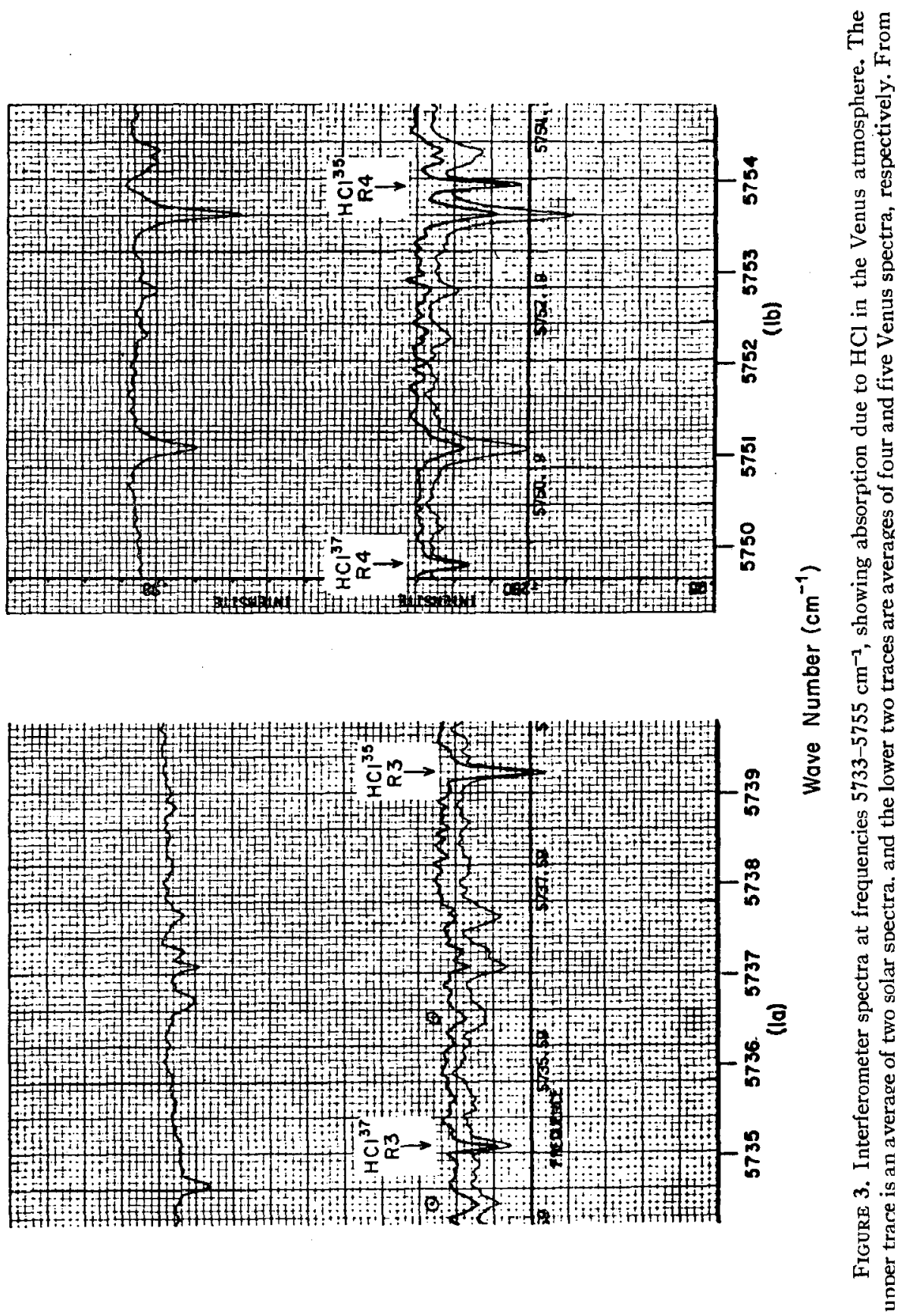

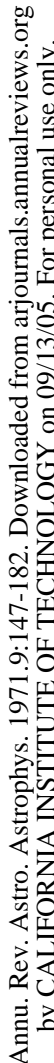


in the lower atmosphere of Mars is CO (Kaplan, Connes \& Connes 1969). They report $\mathrm{CO} / \mathrm{CO}_{2}=0.8 \times 10^{-3}$ by volume, or $5.6 \mathrm{~cm}$-atm $\mathrm{CO}$ above the surface. This is about 25-50 times the amount of $\mathrm{CO}$ in the Earth's atmosphere.

The abundances of $\mathrm{N}_{2}, \mathrm{O}_{2}$, and $\mathrm{CO}$ at or near the surfaces of the Earth, Mars, and Venus are given in Table 1 . The data do not exclude the possibility that the ratio $\mathrm{N}_{2} / \mathrm{CO}_{2}$ is the same on all three planets. The elements $\mathrm{Cl}$ and $\mathrm{F}$ are also listed in Table 1. For Venus, the amounts refer to the mass of $\mathrm{Cl}$ and $\mathrm{F}$ observed in the atmosphere as $\mathrm{HCl}$ and $\mathrm{HF}$. For the Earth, only total abundances are listed. These refer to the $\mathrm{Cl}$ and $\mathrm{F}$ in solution in the oceans (Rubey 1951).

Cloud composition.-Here we consider observations which indicate the existence of clouds or haze in the Venus and Mars atmospheres, and observations which pertain directly to the chemical composition of the cloud particles. Observations of temperatures and pressures, vapor pressure relations, and models of cloud structure will be discussed later.

The reflection spectrum of Venus contains several broadband absorption features which are characteristic of liquid or solid material, as well as numerous narrowband features due to $\mathrm{CO}_{2}$ and other gases. The gaseous features contain little or no evidence of high temperatures and pressures, so the broadband features are presumably characteristic of the cloud particles and not of the planet's surface. Figure 5 shows low-resolution spectra of Venus at wavelengths 0.2-4.0 $\mu$ (Moroz 1965, Bottema et al 1965, Irvine 1968, Kuiper 1969b). Absorptions at 1.5, 2.0, and beyond $3.0 \mu$ are characteristic of ice (Bottema et al 1965, Pollack \& Sagan 1968, Plummer 1970), but $\mathrm{CO}_{2}$ gaseous absorptions may account for the features observed in the Venus spectrum at 1.5 and $2.0 \mu$ (Rea \& O'Leary 1968, Hansen \& Cheyncy 1968). On the other hand, ice is not a strong absorber below $0.4 \mu$, although many other solids are. Kuiper (1969b) has compared these spectra with spectra of many substances, and he concludes that the cloud particles are partially hydrated $\mathrm{FeCl}_{2}$. There is no agreement as to the interpretation of these data.

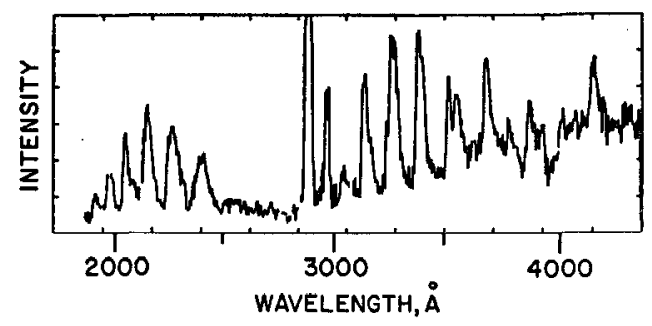

FIGURE 4. Ultraviolet spectrum of the Mars upper atmosphere showing the Cameron bands of $\mathrm{CO}$ below $2600 \AA$, the Fox-Duffendack-Barker bands of $\mathrm{CO}_{2}^{+}$ above $3000 \AA$, the $\mathrm{CO}_{2}{ }^{+}$ultraviolet doublet band system at $2890 \AA$, and the $2972 \AA$ line of atomic oxygen. From Barth et al (1969); copyright, the American Association for the Advancement of Science. 
In principle, it should be possible to derive the refractive index of the cloud particles from measurements of intensity and polarization of reflected sunlight. However, many other effects enter, including the effects of particle size, shape, and orientation with respect to the vertical, and the effects of spatial inhomogeneities within the clouds. At best, one can conclude from existing data that the cloud particles, if they are dielectric spheres, have a refractive index greater than that of water (Arking \& Potter 1968, Coffeen 1969, Hansen \& Arking 1971).

On Mars, several different cloud types can be distinguished, including several kinds of condensation cloud, and dust clouds. Mariners 6 and $7 \mathrm{ob}-$ served two reflection features near $4.3 \mu$ which are highly characteristic of solid $\mathrm{CO}_{2}$ (Herr \& Pimentel 1970). These features were observed on the limb at a height of $25 \pm 7 \mathrm{~km}$. Thin hazes on the limb were also observed in the Mariner 6 and 7 television pictures (Leovy et al 1971), and evidence for a uniform haze was provided by data from the Mariner uv spectrometer (Barth \& Hord 1971). Ground-based polarization data have also been cited as evidence of a uniform haze in the Mars atmosphere (Dollfus \& Focas 1969, Morozhenko 1970), but Ingersoll (1971) has shown that surface polarization and Rayleigh scattering by $\mathrm{CO}_{2}$ can account for all the features cited in these studies.

Ground-based observers frequently report blue-white clouds near the limb and terminator of Mars (Dollfus 1961, Slipher 1962). These clouds of ten occur repeatedly in fixed locations and at fixed times, usually in the afternoon. Several of these repeatedly occurring bright objects were seen by the Mariner 6 and 7 TV cameras (Leovy et al 1971). Their unique diurnal

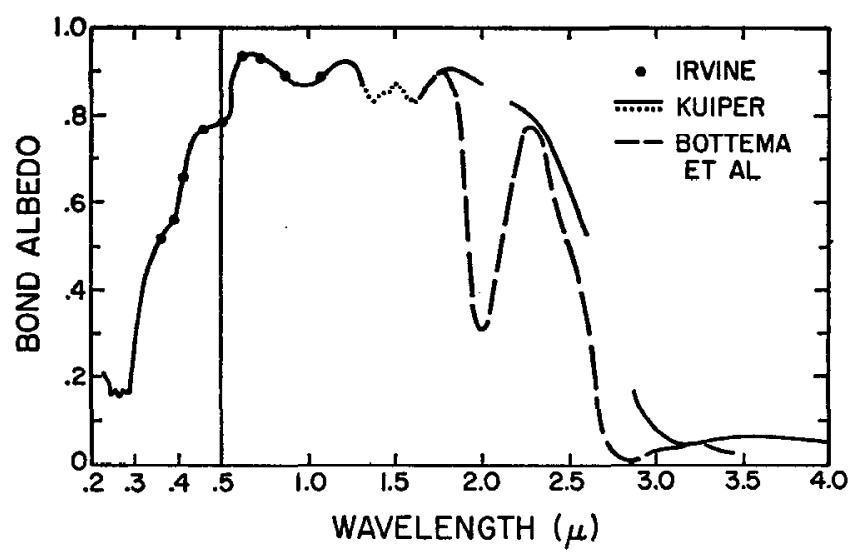

Figure 5. Reflection spectrum of Venus from $0.2 \mu$ to $4.0 \mu$. Bond albedo is the ratio of total light reflected by the planet to total light incident. Irvine's (1968) points and Kuiper's (1969b) curve are replotted from Kuiper (1969b). The un-normalized data of Bottema et al (1965) are replotted so as to agree with Kuiper's data at 1.6$1.7 \mu$. 
brightening behavior suggests that these are also a condensation phenomenon.

Bright, yellow clouds are also seen by ground-based observers. They are generally thought to be dust clouds which arise in the bright, yellow areas. Although infrequent, they occasionally obscure the entire planet, and may last for several weeks (Dollfus 1961, Pollack \& Sagan 1970).

Some observers feel that there is evidence of a "blue haze" in the atmosphere of Mars. The dark maria are normally invisible in ground-based photographs taken through a blue filter, but there are sometimes "blue clearings" during which these features become faintly visible. However, the Mariner 6 and $7 \mathrm{TV}$ pictures showed that crater visibility was the same in pictures taken with a blue filter as in pictures taken with red or green filters (Leighton et al 1969). Moreover, the normal invisibility of the maria in blue light can be explained as a surface phenomenon (McCord 1969, Pollack \& Sagan 1969, McCord \& Westphal 1971), and the blue clearings, which occur mostly near opposition, can be explained as an effect of the surface phase function (Slipher 1962, O'Leary 1967). The only difficulty is that blue clearings do occasionally occur far from opposition (de Vaucouleurs 1968, Capen 1970), so the possibility remains that a thin blue haze does affect the visibility of surface phenomena.

\section{Structure of the Lower Atmospheres}

Several convenient properties distinguish planetary lower atmospheres from upper atmospheres. First, temperature is well defined in the lower atmospheres; the population of molecular vibration and rotation states follows a Boltzmann distribution. Second, lower atmospheres are well mixed; the proportion of noncondensable gaseous constituents is the same at all levels. And third, recombination is swift; the effects of photodissociation and photoionization can generally be ignored. In this section we shall consider the characteristics of the Venus and Mars lower atmospheres: their thermal structures, the Venus cloud structure, and theories of the thermal structures. This subject was reviewed by Goody (1969), and the following discussion will therefore focus on the more recent observational and theoretical developments.

Thermal structure.-Vertical profiles of temperature and pressure in the lower atmospheres have been determined from direct measurements made by Veneras 4,5 , and 6 , and from radio occultation measurements made by Mariners 4, 6, and 7 at Mars and by Mariner 5 at Venus. The derived profiles depend on the assumed composition of the lower atmosphere, but this is not a major source of error. These methods are extremely powerful, and a wealth of detailed information has been obtained.

Figure 6 shows the most recent analysis of temperature vs distance to the center of Venus, based on Mariner 5 refractivity data (Fjeldbo, Kliore \& Eshleman 1971). The Venera 4, 5, and 6 data agree with these results, al- 
though absolute height is uncertain in the Venera data (Avduevsky, Marov \& Rozhdestvensky 1970). The Venera data extend deeper into the atmosphere (to $P \approx 27 \mathrm{~atm}$ ), but the Mariner data extend farther up, and show considerably more fine structure.

The lapse rate of temperature is within a few percent of the adiabatic rate, at least from $20 \mathrm{~km}$ altitude $(P \approx 27 \mathrm{~atm})$ up to $60 \mathrm{~km}$. If the adiabatic lapse rate is extrapolated down to the surface, temperatures are obtained which are in reasonable agreement with surface temperatures determined from microwave data (Figure 1), and with the $747 \pm 20^{\circ} \mathrm{K}$ surface temperature measured by the Soviet space probe Venera 7 (Advuevsky et al 1971). If there is an isothermal layer next to the ground (Gale, Liwshitz \& Sinclair 1969, Muhleman 1969), its thickness must be less than about $3 \mathrm{~km}$.

The fine structure shown in Figure 6 is also significant. The abrupt changes in lapse rate at altitudes of 50 and $60 \mathrm{~km}$ may indicate a transition from dry to wet adiabatic conditions, implying that clouds are forming at

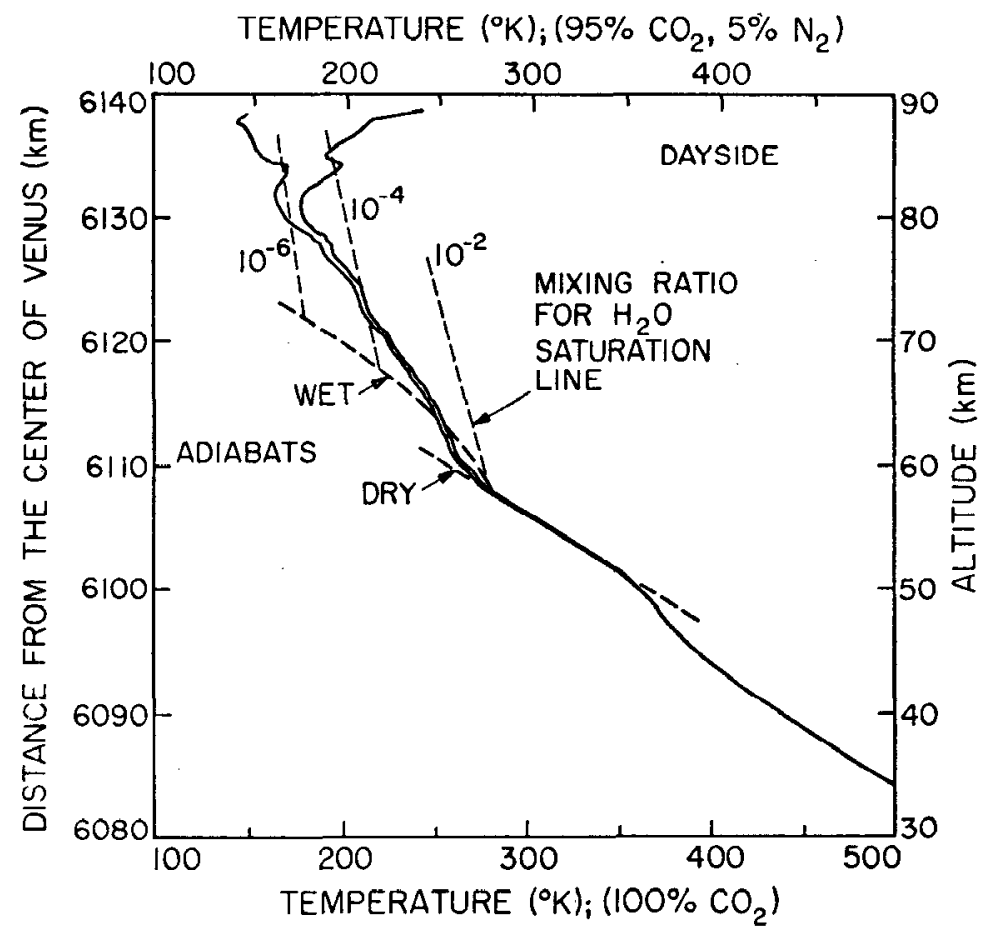

FIGURE 6. Temperature profiles of Venus from refractivity data by assuming a mixed atmosphere in hydrostatic equilibrium. Also shown are saturation lines for water vapor and adiabatic profiles for a dry and a wet (mass mixing ratio of $10^{-2}$ ) atmosphere. From Fjeldbo, Kliore \& Eshleman (1971); copyright, the American Astronomical Society. 
these two levels. The region below $50 \mathrm{~km}$ is also a source of attenuation at $2297 \mathrm{MHz}$ (Fjeldbo, Kliore \& Eshleman 1971). Possible sources of attenuation at these levels are dust, turbulence (de Wolf 1970), and clouds of mercury halides (Rasool 1970).

The radio occultation experiments on Mariners 4, 6, and 7 provide data about the thermal structure of the Mars atmosphere (Kliore et al 1969b, Rasool et al 1970). Figure 7 shows the temperature profiles at the entry and exit points for Mariners 6 and 7 . The profiles are uncertain at high altitudes, because of uncertainties in the motion of the spacecraft and in the refractivity of the ionosphere. Nevertheless, all published analyses of these data show an extremely cold region in the middle atmosphere, with derived temperatures falling below the saturation curve of $\mathrm{CO}_{2}$. The point at which each profile crosses the saturation curve is indicated by a shaded line in Figure 7. Other features of importance in the Figure 7 profiles are: the subadiabatic

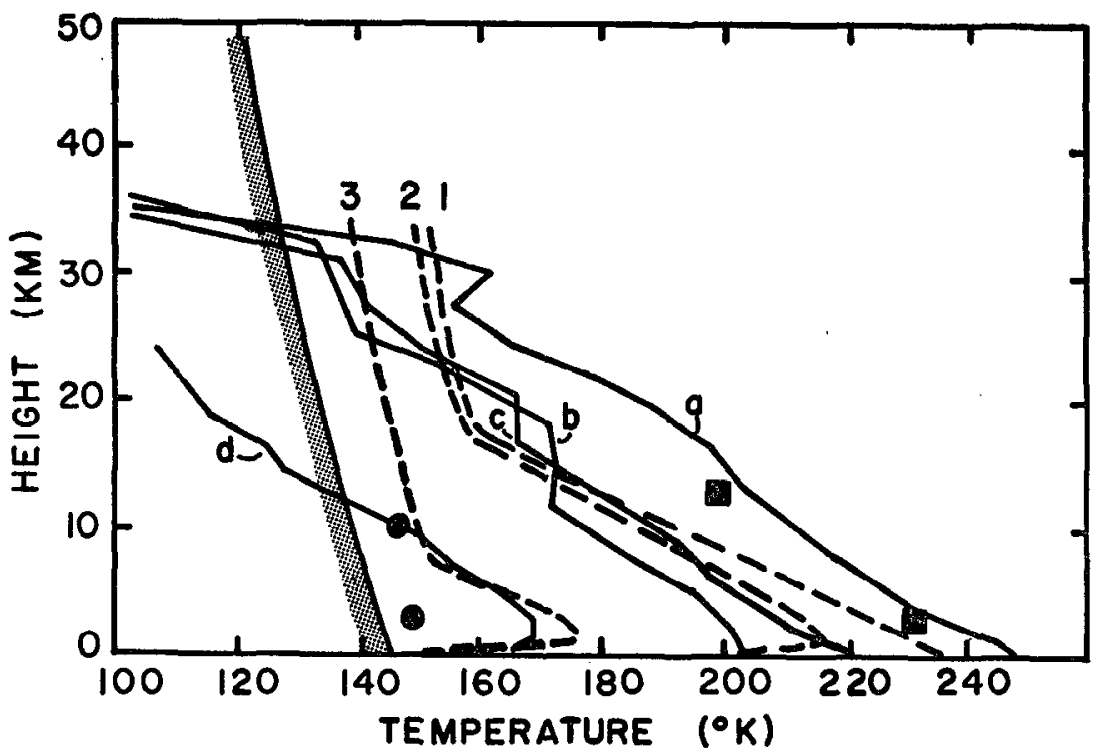

Figure 7. Thermal structure of the lower atmosphere of Mars. The solid lines are from Mariner 6 and 7 radio occultation data, as analyzed by Rasool et al (1970): a. latitude $3.7^{\circ} \mathrm{N}$, local time 1545 ; b. latitude $38.1^{\circ} \mathrm{N}$, local time 0310 ; c. latitude $58.2^{\circ} \mathrm{S}$, local time 1430 ; d. latitude $79.3^{\circ} \mathrm{N}$, local time 2210 (all for northern hemisphere early fall). The dashed lines are from the static model calculations of Gierasch $\&$ Goody (1968): 1 . equator equinox, local time $1600 ; 2$. equator equinox, local time $0400 ; 3.45^{\circ} \mathrm{N}$ winter, local time 0800 . The points are from the dynamic model calculations of Leovy \& Mintz (1969): squares-equator, northern winter, local time 1600 ; circles- $75^{\circ} \mathrm{N}$ winter, local time 2200 . The shaded line is the $\mathrm{CO}_{2}$ saturation vapor pressure curve. 
lapse rate (about $3.5^{\circ} \mathrm{K} / \mathrm{km}$, or $70 \%$ of the adiabatic rate), observed in all the profiles, the strong inversion at the autumn pole (profile $\mathrm{d}$ ), and the highly unstable temperature discontinuity at the equator during the day (profile a). The later discontinuity is indicated by comparing the atmospheric temperature near the ground, $T \approx 250^{\circ} \mathrm{K}$, with the surface temperature, $T \approx 275$, measured with the Mariner infrared radiometer (Neugebauer et al 1969).

Venus cloud structure.-Venus exhibits limb darkening in the thermal infrared, as shown in Figure 8 (Murray, Wildey \& Westphal 1963, Westphal 1966). This suggests either that the visibility within the cloud is largeabout one scale height (Samuelson 1968) - or that the cloud-top surface is bumpy and irregular: These alternatives are also suggested by studies of optical phenomena near inferior conjunction (Goody 1967, Schilling \& Moore 1967, Abhyankar 1968). The near uniformity of integrated disk
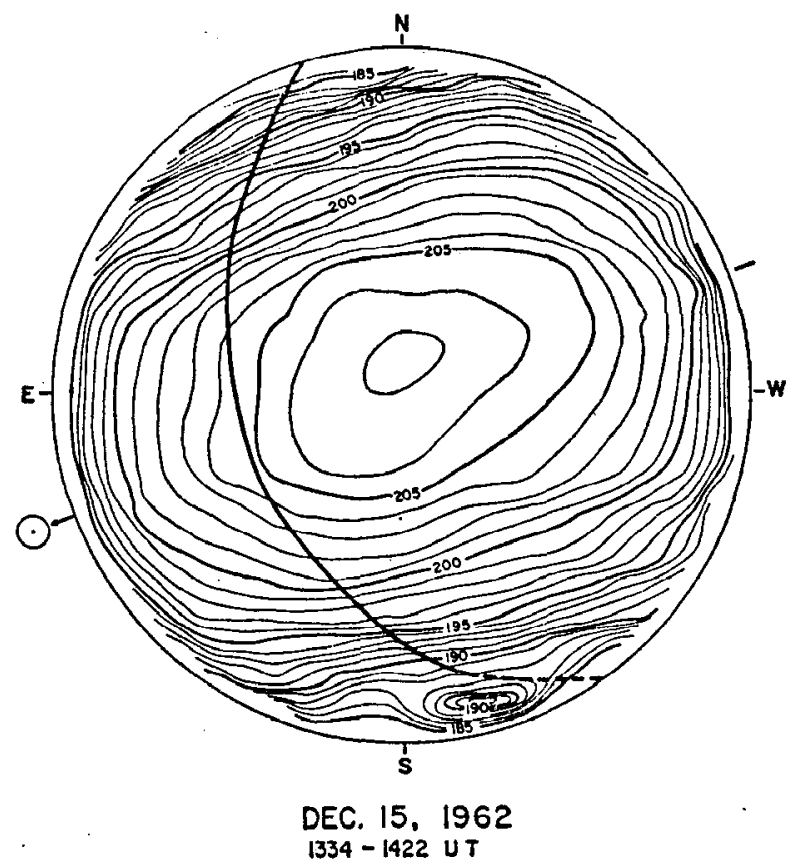

Figure 8. Brightness temperature map of Venus $(8-14 \mu)$ for the morning of December 15, 1962. The terminator and the projected direction to the Sun are indicated, respectively, by the heavy line and by the symbol. The slightly crenelated pattern running in the east-west direction results from uncertainties in positioning the scans. The brightness temperatures shown are systematically too low because of uncertain telescope transmission losses. From Murray, Wildey \& Westphal (1963); copyright, the American Geophysical Union. 
temperature at wavelengths from 4 to $14 \mu$ serves to define a mean emission temperature for the cloud. Measured values of the emission temperature fall in the range $215-250^{\circ} \mathrm{K}$ (Sinton 1963, Gillett, Low \& Stein 1968, Hanel et al 1968).

Spectroscopic studies define an effective cloud temperature which is comparable to the emission temperature. They also provide evidence that the optical path of reflected sunlight varies by at least one scale height. The observed increase of gaseous absorption toward superior conjunction indicates that sunlight travels at least one scale height farther in the atmosphere at normal incidence than it does at grazing incidence (Chamberlain 1965, Moroz 1968). In addition the strengths of gaseous absorptions vary erratically with time and with position on the disk (Kuiper 1969b, Young, Schorn \& Smith 1970).

Temperatures derived from rotational analyses of $\mathrm{CO}_{2}$ bands fall in the range $220-280^{\circ} \mathrm{K}$ (Belton, Hunten \& Goody 1968 , Belton 1968 , Young, Schorn \& Smith 1970 ), although temperatures as high as $450^{\circ} \mathrm{K}$ have been inferred (Spinrad 1966). The effective pressures generally fall in the range 100-200 mb, although the effective pressure may be as low as $50 \mathrm{mb}$ for strong bands, and as high as $500 \mathrm{mb}$ for weak bands (Young 1970). It is tempting to associate these effective temperatures and pressures with a specific level in Figure 6 . The level $T=240^{\circ} \mathrm{K}, P \approx 100 \mathrm{mb}$ occurs at about 66 $\mathrm{km}$, approximately $6 \mathrm{~km}$ above the level of transition from adiabatic to subadiabatic lapse rate.

If the clouds are water clouds with bases at $60 \mathrm{~km}$, then the water vapor mixing ratio must fall from $10^{-2}$ at the cloud base to $10^{-3}$ at the level of spectral line formation. This means that the partial pressure of water vapor must be about $0.1 \mathrm{mb}$ at the level of line formation, and in order that this amount be consistent with spectroscopic abundances (less than $100 \mu$ precipitable water above the level of line formation), the scale height of water vapor must be less than $1 \mathrm{~km}$. In fact, this is about one-half the scale height one obtains using the observed temperature gradient to define a vapor pressure scale height. Given the uncertainties in defining the level of line formation, these numbers are not inconsistent. The fact that temperature falls to $180^{\circ} \mathrm{K}$, according to Figure 6 , suggests that the clouds of Venus may be water clouds, provided the level of line formation is sufficiently high in the atmosphere. It must be remembered, however, that these arguments do not establish that the clouds are water, and they do not exclude the possibility of cloud constituents other than water.

Theories of the thermal structure.--There are many theories of the high surface temperatures on Venus, and it is still not possible to choose between them. We do not know the profiles of solar heating or of infrared emission below about one optical depth in the atmosphere. Such information could be obtained by means of an entry probe on the sunlit side of the planet, and such a probe is well within the United States' and Soviets' technological capacities 
(Hunten \& Goody 1969). We also do not know the opacities of $\mathrm{CO}_{2}$ and other atmospheric constituents under conditions which prevail in the lower Venus atmosphere. Existing laboratory data cannot settle the important question whether there is significant absorption in the wings of gaseous absorption lines and in the windows between vibration-rotation bands (Plass \& Stull 1963).

Theories of the thermal structure of the Venus atmosphere differ as to how the surface is heated, and how the heat is trapped near the surface. Trapping may be due to reflection of upward-propagating radiation at the base of the cloud (Avduevsky et al 1970), absorption by dust in the lower atmosphere (Hansen \& Matsushima 1967), absorption and reflection by dust in the lower atmosphere (Samuelson 1967), or absorption by atmospheric gases (Sagan 1960, Ohring 1969, Pollack 1969). Most workers feel that absorption by $\mathrm{CO}_{2}$ alone does not provide the opacity necessary to maintain high surface temperatures with an adiabatic lower atmosphere. Unless the heat source at the surface were many times greater than the solar constant, a pure $\mathrm{CO}_{2}$ atmosphere would cool to temperatures below the present value, and an extensive isothermal layer would develop. Water vapor in concentrations $10^{-3}$ to $10^{-2}$, together with $\mathrm{CO}_{2}$, could provide the necessary opacity, but the extrapolation to high temperatures and pressures is uncertain.

Theories of the mechanism of heat deposition at the Venus surface also differ. In the greenhouse models, heat is deposited directly by sunlight, either at the surface or in the lower atmosphere (Sagan 1960, Pollack 1969, Ohring 1969). In the internal heating models, no solar heat is deposited, but the infrared opacity of the atmosphere is so great that planetary heat can maintain the high surface temperatures (Hansen \& Matsushima 1967). In the dynamical models, energy is convected downward by large-scale motions driven by solar heating at the top of the atmosphere (Goody \& Robinson 1966). Gierasch \& Goody (1970) argue that convection of heat by large-scale motions is the most effective means of heating the deepest levels. They point out that unless convection extends to the ground, cloud particles of dust or low-vapor-pressure condensate will fall out, and the cloud will collapse. Gierasch \& Goody do not consider clouds of water or other high-vaporpressure condensates, mainly because they feel such clouds are excluded by optical and spectroscopic data. Without direct entry probes into the Venus atmosphere, it is unlikely that any of these questions will be settled.

Theories of the thermal structure of the Mars atmosphere differ from those of Venus and the Earth in that the Mars atmosphere has only a small effect on temperatures at the ground. This is due partly to the small heat capacity of the Mars atmosphere and partly to the small optical thickness of the atmosphere at most visible and infrared wavelengths. With these assumptions, Leighton \& Murray (1966) showed that the partial pressure of $\mathrm{CO}_{2}$ in the atmosphere might be controlled by the vapor pressure of solid $\mathrm{CO}_{2}$ at the pole. Subsequent observations have shown that the polar caps 
are indeed $\mathrm{CO}_{2}$ (Herr \& Pimentel 1969) and are at the temperature necessary for equilibrium with the atmosphere (Neugebauer et al 1969).

Because the radiative adjustment time for atmospheric temperature is short (Goody \& Belton 1967), the atmospheric temperatures tend to "follow" the temperature of the ground during the diurnal cycle. Gierasch \& Goody (1968) have computed temperature profiles vs time of day for a radiating, convecting model of Mars (Figure 7). The significant features of these profiles are the absence of $\mathrm{CO}_{2}$ condensation except at the ground near the pole, the nearly constant, adiabatic lapse rate throughout most of the atmosphere, the strong night-time inversions due to cooling of the ground, and the highly unstable temperature discontinuities (up to $70^{\circ} \mathrm{K}$ ) at the ground during the day. Recently, Gierasch (1971) has examined a general class of radiating, convecting models of the Mars atmosphere. He shows that very low temperatures, below the $\mathrm{CO}_{2}$ saturation line, are thermodynamically possible, but that the atmosphere must function as an extremely efficient heat engine for these low temperatures to occur. That is, rising convective elements, driven by heating at the surface, would have to overshoot the height at which they are neutrally bouyant, with little dissipative energy loss. There is no evidence that such efficient convection takes place in laboratory or terrestrial situations.

\section{Structure of the Upper Atmospheres}

At sufficiently high atmospheric levels, local thermodynamic equilibrium breaks down and energy cannot be efficiently radiated away by molecular vibration-rotation bands in the thermal infrared. This breakdown occurs when the spontaneous emission probability per molecule exceeds the rate of excitation by collisions. On the Earth, Venus, and Mars, the LTE transition level is determined by relaxation of the lowest vibrational mode of $\mathrm{CO}_{2}$, centered at $667 \mathrm{~cm}^{-1}$. This occurs at a pressure of about $0.3 \times 10^{-2} \mathrm{mb}$ on all three planets. Since energy absorbed above the transition level can only be removed by conduction or mass transport downward, this level is also a temperature minimum, which, in the case of the Earth, is called the mesopause. In this section we shall consider the characteristics of the Mars and Venus atmospheres from the mesopause upward. Following usage for the Earth, we shall sometimes refer to two subdivisions of this upper atmosphere region: the thermosphere, in which the mean free path of molecules is less than a scale height, and the exosphere, in which the mean free path exceeds a scale height.

Observations.-The atmospheric refractive indices deduced from radio occultation of Mariners 4, 5, 6, and 7 yield information on upper-atmosphere structure as well as on the density profile near the ground. Refractive indices less than one arise from ionization, and electron densities can be inferred from the portions of the occultation data exhibiting such refractive indices. Figure 9 shows electron densities on the day sides of Venus and Mars in the 
height range 90 to $200 \mathrm{~km}$ deduced from Mariner 4, 5, and $6 \mathrm{~S}$-band occultation data (Kliore et al 1967, 1969a, 1969b, Fjeldbo \& Eshleman 1968, Fjeldbo, Kliore \& Seidel 1970). Electron densities at higher levels on the day and night sides of Venus, inferred from the dual frequency radio occultation experiment of Mariner 5, are shown in Figure 10 (Mariner Stanford Group 1967). No ionization was detected on the night sides of either Venus or Mars by the S-band technique.

Information on the state of the upper atmosphere also comes from ultraviolet photometry on Mariner 5, and ultraviolet spectrometry on Mariners 6 and 7. The intensity of emissions can be directly related to number densities of ground states as well as of the emitting states, provided that the excitation mechanisms are known (Barth 1969). Mariner 5 detected emission in the 1050-1250 $\AA$ band, presumably due to Ly $\alpha$ (Barth, Pearce \& Kelley et al 1967, Barth, Wallace \& Pearce 1968). These data are shown in Figure 11. Ultraviolet photometers carried by Venera 4 also detected Ly $\alpha$ emission near Venus; intensities agree with the data shown in Figure 11 at distances exceeding $12,000 \mathrm{~km}$ on the day side, but showed lower emission rates closer to the planet. An attempt to detect the 1304-7 $\AA$ atomic oxygen emission by Venera 4 yielded negative results, from which an upper-limit atomic oxygen abundance of $2 \times 10^{3}$ atoms $/ \mathrm{cm}^{8}$ at $300 \mathrm{~km}$ height has been inferred (Kurt, Dostolow \& Sheffer 1968). Ly $\alpha$ was also detected near Mars (Barth et al 1969), as were the spectral features of $\mathrm{CO}, \mathrm{O}, \mathrm{CO}_{2}{ }^{+}$shown in Figure 4.

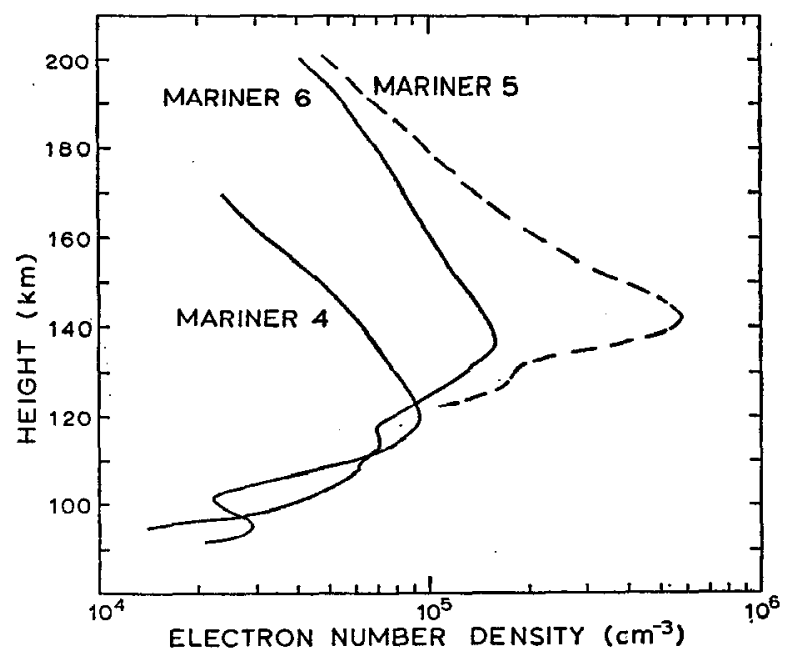

FigURE 9. Electron number densities for Mariner 4 (replotted from Fjeldbo \& Eshleman 1968), Mariner 5 (replotted from Kliore et al 1967), and Mariner 6 (replotted from Fjeldbo, Kliore \& Seidel 1970). The solar zenith angle was $67^{\circ}$ at Mars for Mariner $4,33^{\circ}$ at Venus for Mariner 5 , and $57^{\circ}$ at Mars for Mariner 6 . The Mariner 7 electron density was nearly identical to that of Mariner 6. 
An absolute density datum for the Venus upper atmosphere was obtained from the 1959 occultation of Regulus (deVaucouleurs \& Menzel 1960, Hunten \& McElroy 1968). Density $118 \mathrm{~km}$ above the surface was approximately $6 \times 10^{18}$ molecules $/ \mathrm{cm}^{8}$. This density value agrees with the upward extrapolation of density inferred from the Mariner 5 radio occultation (Figure 12). No comparable neutral density datum is available for the Mars mesopause region.

Composition and thermal structure.-When theoretical models of the Mars and Venus thermospheres are compared with observation, only those models involving essentially pure $\mathrm{CO}_{2}$ give good agreement. Compared with all combinations of $\mathrm{H}, \mathrm{C}, \mathrm{O}, \mathrm{N}$, their compounds of moderate molecular weight, and rare gases, pure $\mathrm{CO}_{2}$ gives an extremum of thermospheric properties. Models involving pure $\mathrm{CO}_{2}$ give the smallest electron densities, the lowest elevation for the electron density peak, and the smallest electron scale height above the peak. These properties of pure $\mathrm{CO}_{2}$ thermospheres result from the high molecular weight and radiative efficiency of $\mathrm{CO}_{2}$, which imply low temperatures and small scale heights.

Static thermal and ionization models of Venus illustrate this (Stewart 1968, Gross, McGovern \& Rasool 1968, Stewart \& Hogan 1969a, McElroy

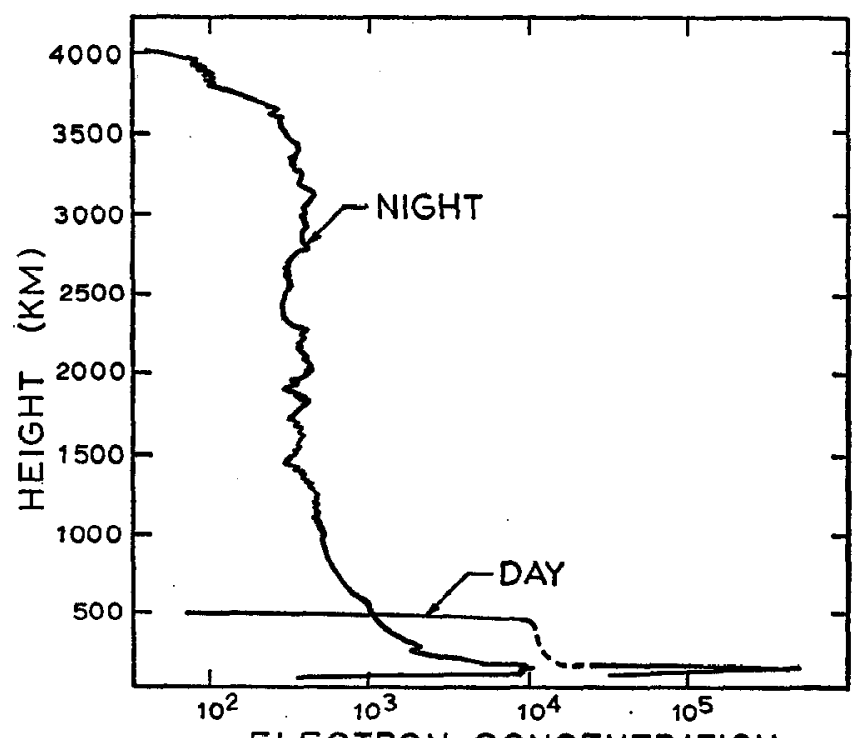

ELECTRON CONCENTRATION

FigURE 10. Day and night side electron densities for Venus from the Mariner 5 dual frequency occultation experiment (Mariner Stanford Group 1967). The dashed portion of the day curve indicates missing data due to the formation of caustics. 
1967, 1969). These models show that the observed Venus electron density profile (Figure 9) can be explained by ionization of $\mathrm{CO}_{2}$ and dissociative recombination $\left(\mathrm{CO}_{2}{ }^{+}+\mathrm{e}^{-} \rightarrow \mathrm{CO}+\mathrm{O}\right)$, with an upper thermosphere temperature near $700^{\circ} \mathrm{K}$. They also show that as little as $2.5 \%$ dissociation $\left(\mathrm{O} / \mathrm{CO}_{2}\right.$ $=2.5 \%$ ) at $135 \mathrm{~km}$, with diff usive equilibrium above $135 \mathrm{~km}$, produces large increases over the observed electron densities at high elevation due to ionization of a tomic oxygen. Similarly, only $10 \% \mathrm{~N}_{2}$ by volume, mixed throughout the thermosphere, produces marked excesses of electrons relative to the observations. Using a complex model of diffusion, ionization charge exchange, and recombination processes, Shimizu (1969) has shown that electron density and height of the ionization peak increase dramatically as lighter gases are added to $\mathrm{CO}_{2}$.

These results are consistent with the very low limit on atomic oxygen obtained from Venera 5 observations at 1304-7 $\AA$ (Kurt, Dostolow \& Sheffer 1968). If we combine that negative result with the density datum obtained from the Regulus occultation, and assume an upper thermosphere temperature of $700^{\circ} \mathrm{K}$, the $\mathrm{O} / \mathrm{CO}_{2}$ ratio at $300 \mathrm{~km}$ would be $<10^{-4}$. A rocket ultraviolet spectrum of Venus showing an atomic oxygen feature indicates that this limit may be too low, however (Moos, Fastie \& Bottema 1969). The $700^{\circ} \mathrm{K}$ temperature inferred from the ionization profile agrees with that of atomic hydrogen in the exosphere at planetocentric distances exceeding $12,000 \mathrm{~km}$, as determined from the Ly $\alpha$ emission (Barth 1968). Some results of McElroy's (1969) static thermal model of the Venus thermosphere are shown in Figure 12. These results agree with those of Stewart (1968) and Hogan \& Stewart (1969).

Although a variety of Mars electron density models have been considered (see Brandt \& McElroy 1968, McElroy 1967), only models for which $\mathrm{CO}_{2}{ }^{+}$is

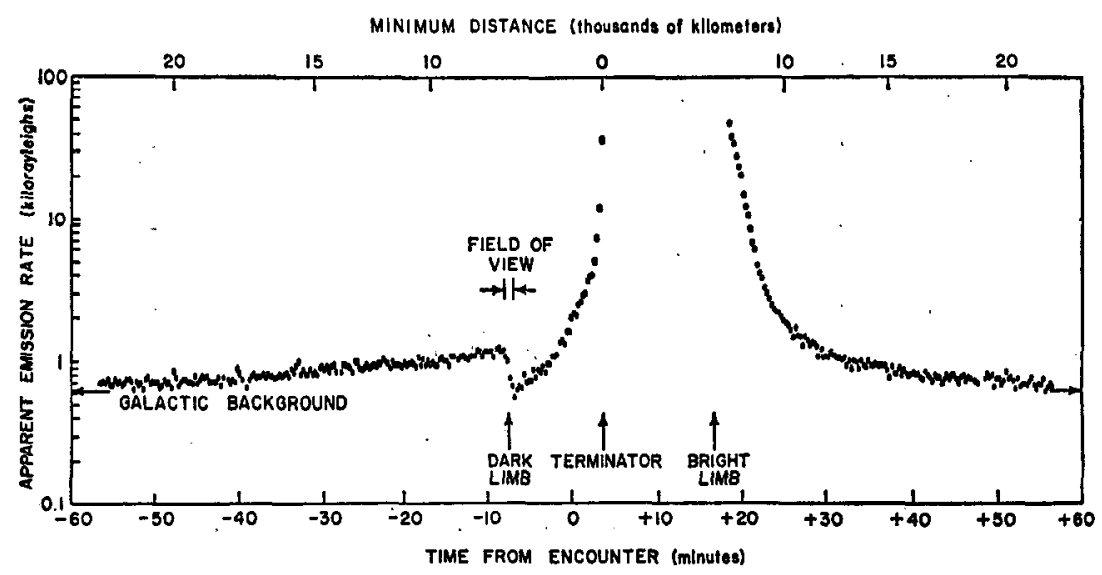

Figure 11. Lyman $\alpha$ emission observed at Venus by Mariner 5. From Barth et al (1967); copyright, the American Association for the Advancement of Science. 
the predominant positive ion between 150 and $200 \mathrm{~km}$ appear to be acceptable when the most recent laboratory measurement of the rate of dissociative recombination of $\mathrm{CO}_{2}{ }^{+}$is used (Weller \& Biondi 1967). The ultraviolet spectra (Figure 4) confirm the predominance of $\mathrm{CO}_{2}^{+}$. The $\mathrm{O}$ and $\mathrm{CO}$ emissions in the ultraviolet spectra have been shown to be consistent with an $\mathrm{O} / \mathrm{CO}_{2}$ ratio of $10^{-3}$ at $140 \mathrm{~km}$, and $10^{-2}$ at $200 \mathrm{~km}$ (McConnell \& McElroy 1970). The low, thin, and weak ionized layer on Mars is again an indication that concentrations of any lighter gases, such as $\mathrm{N}_{2}$, are very low. As we have seen, the ultraviolet spectra provide even stronger evidence for a low $\mathrm{N}_{2}$ abundance.

If we assume that the electron density profile is determined by ionization and dissociative recombination, the scale height above the peak indicates a Mars upper thermosphere temperature near $300^{\circ} \mathrm{K}$ in July 1965 (Stewart \& Hogan 1969b, Hogan \& Stewart 1969), and near $500^{\circ} \mathrm{K}$ in August 1969 (Fjeldbo, Kliore \& Seidel 1970). The difference can be explained by the greater extreme ultraviolet (euv) solar flux in 1969.

According to McElroy (1969), the upper thermosphere temperature expected for Mars in July 1965 is about $450^{\circ} \mathrm{K}$, significantly greater than the $300^{\circ} \mathrm{K}$ temperature inferred from the electron scale height. Cloutier, McElroy \& Michel (1969) suggested that solar wind interaction with the Mars thermosphere could drive ionization downward on the day side, and might explain the low value of the electron scale height. They assume that the Venus thermosphere is shielded from this effect by atomic hydrogen in the

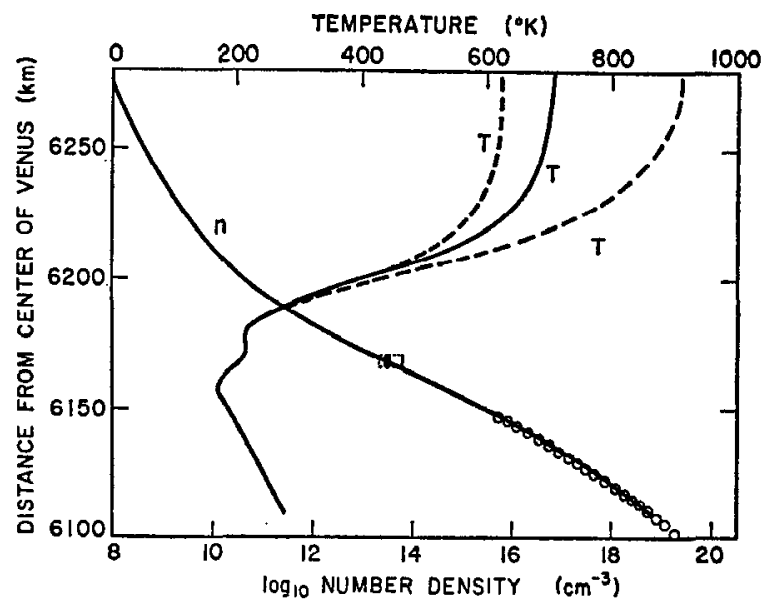

FIGURE 12. Temperature and density of the upper atmosphere of Venus according to McElroy's model. Solid curves are for Mariner 5 conditions; dashed curves are for solar maximum and minimum. Open circles are densities inferred from the S-band experiment on Mariner 5 . The rectangle at $6170 \mathrm{~km}$ is density from the Regulus occultation data. From McElroy (1969); copyright, the American Geophysical Union. 
exosphere. On the other hand, Hogan \& Stewart (1969) argue that the photoionization heating efficiency in a $\mathrm{CO}_{2}$ atmosphere may be smaller than the value assumed by McElroy, and that this may account for the $300^{\circ} \mathrm{K}$ temperature inferred from the electron scale height on Mars (Figure 13). They then account for the $700^{\circ} \mathrm{K}$ temperature inferred for Venus as an effect of that planet's slow rotation; relatively high temperatures develop on the dayside (Figure 12), in spite of the presumed low value of the heating efficiency, because the thermal response time of the thermosphere is short compared to the period of rotation. It remains to be seen whether a low value of the heating efficiency can be reconciled with laboratory and theoretical studies (Henry \& McElroy 1968, McConnell \& McElroy 1970).

Photochemistry of $\mathrm{CO}_{2}$. - It is surprising that the upper atmospheres of Venus and Mars consist almost entirely of undissociated $\mathrm{CO}_{2}$. Direct three-body recombination,

$$
\mathrm{CO}+\mathrm{O}+\mathrm{M} \rightarrow \mathrm{CO}_{2}+\mathrm{M}
$$

has a rate coefficient less than $10^{-34} \mathrm{~cm}^{6} / \mathrm{sec}$ (Clyne $\&$ Thrush 1962). This is fast enough to account for recombination and predominance of $\mathrm{CO}_{2}$ in the lower atmosphere, but not in the thermosphere. Turbulent mixing of dissociation products downwards, and of $\mathrm{CO}_{2}$ upwards, could account for the undissociated state of the thermosphere, but only if the mixing rate were several orders of magnitude greater on Mars and Venus than it is on the Earth at comparable levels (Donahue 1968, Shimizu 1969). There is no obvious reason why both Mars and Venus should have such high mixing rates in their upper atmospheres.

Several authors have proposed that $\mathrm{O}$ and $\mathrm{CO}$ recombine in the upper atmosphere through formation of intermediate states or catalysis by minor constituents, but there are strong arguments against each proposed mech-

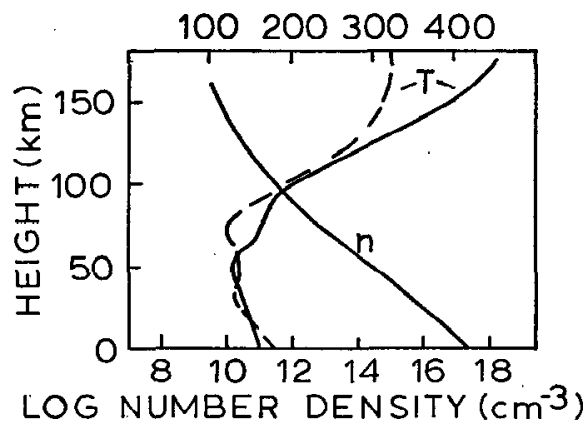

Figure 13. Temperature and density of the upper atmosphere of Mars computed from different atmospheric models. Solid lines are from McElroy (1969); the dashed line is from Hogan \& Stewart (1969). 
anism. McElroy (1967) and McElroy \& Hunten (1970) suggested that $O$ and $\mathrm{CO}$ would recombine in the following reactions:

$$
\begin{array}{ll}
\mathrm{O}^{1} \mathrm{D}+\mathrm{CO}_{2} \rightarrow \mathrm{CO}_{3}^{*} & 2 . \\
\mathrm{CO}_{3}+\mathrm{CO} \rightarrow 2 \mathrm{CO}_{2} & 3 .
\end{array}
$$

Excited atomic oxygen $\left(\mathrm{O}^{1} \mathrm{D}\right)$ is produced in the dissociation of $\mathrm{CO}_{2}$ by euv radiation. The excited $\mathrm{CO}_{3}\left(\mathrm{CO}_{3}{ }^{*}\right)$ undergoes a radiative transition to a stable state. This state must last for at least $20 \mathrm{sec}$ in order that the rate at which reaction (3) proceeds be sufficient to prevent accumulation of $\mathrm{CO}$ and $O$ (Donahue 1968). However, there is now strong experimental evidence that the lifetime of $\mathrm{CO}_{3}$ is negligibly small, and that the quantum efficiency for production of $\mathrm{CO}$ and $\mathrm{O}$ in the ground state is unity (DeMore 1970, Clark \& Noxon 1970, Felder, Morrow \& Young 1970, Slanger \& Black 1970).

Donahue (1968) has suggested that recombination is catalyzed by hydrogen compounds produced in the dissociation of $\mathrm{H}_{2} \mathrm{O}$ :

$$
\begin{array}{ll}
\mathrm{CO}+\mathrm{OH} \rightarrow \mathrm{CO}_{2}+\mathrm{H} & 4 . \\
\mathrm{H}+\mathrm{O}_{2}+\mathrm{M} \rightarrow \mathrm{HO}_{2}+\mathrm{M} & 5 . \\
\mathrm{HO}_{2}+\mathrm{CO} \rightarrow \mathrm{CO}_{2}+\mathrm{OH} & 6 .
\end{array}
$$

With an ample supply of $\mathrm{H}$ and $\mathrm{OH}$, this mechanism would be limited by the three-body reaction (5). Consequently, it would only be effective below the mesopause. Rapid vertical mixing of $\mathrm{O}, \mathrm{CO}$, and $\mathrm{CO}_{2}$ would be required for these reactions to affect the state of $\mathrm{CO}_{2}$ dissociation in the thermosphere.

None of these mechanisms appears to be satisfactory, especially in view of the fact that the real recombination mechanism works on both Venus and Mars, even though hydrogen compound concentrations and turbulent mixing rates are likely to be quite different on the two planets.

Hydrogen, deuterium, and helium on Venus.-The Mariner 5 Ly $\alpha$ observations at Venus (Figure 11) cannot be interpreted in terms of a single component in thermal escape. The dayside data are consistent with a number density distribution having a scale height of $800 \mathrm{~km}$ below $6000 \mathrm{~km}$ altitude, and a scale height of $1600 \mathrm{~km}$ above $6000 \mathrm{~km}$. If the neutral exosphere densities are a consequence of thermal escape, two Ly $\alpha$ emitting components, whose ratio of scale heights is 2, are required to explain these data. Barth, Wallace \& Pearce (1968) suggested that photodissociation of $\mathrm{H}_{2}$ yielding $\mathrm{H}(2 P)$ followed by Ly $\alpha$ emission could explain the smaller scale height below $6000 \mathrm{~km}$, but the high ratio of $\mathrm{H}_{2}$ to $\mathrm{H}\left(\sim 10^{5}\right)$, which would be required to explain the observations, could not be maintained against photodissociation by any plausible transport mechanism (Donahue 1968, McElroy \& Hunten 1969).

Alternatively, the small scale height below $6000 \mathrm{~km}$ could be due to deuterium (Donahue 1968). This hypothesis requires an $\mathrm{H}$ concentration of 
$10^{4} \mathrm{~cm}^{-3}$ and a $\mathrm{D}$ concentration of $10^{5} \mathrm{~cm}^{-3}$ at the base of the exosphere (Wallace 1969). Such a low H/D ratio need not require a low $H / D$ ratio in the atmosphere as a whole. Because $H$ escapes much more readily than $D$, the escape flux of $\mathrm{H}$ would exceed that of $\mathrm{D}$ by the factor $2 \times 10^{3}$, and if every $\mathrm{H}$ and $\mathrm{D}$ atom produced by primary photodissociation escapes, this would also be the ratio H/D in the atmosphere as a whole (Donahue 1968). The large change in the ratio $\mathrm{H} / \mathrm{D}$, from $2 \times 10^{3}$ in the lower atmosphere to $10^{-1}$ at the base of the exosphere, implies weaker vertical mixing in the Venus upper atmosphere than on the Earth (McElroy \& Hunten 1969, Donahue 1969). This is at odds with the apparent requirement for intense mixing needed to maintain a $\mathrm{CO}_{2}$ thermosphere. For the Earth, the ratio $\mathrm{H} / \mathrm{D}$ is 6700 . McElroy \& Hunten suggest that $H$ has been depleted relative to $D$ on Venus as a result of fractionation by escape of large amounts of hydrogen. Since hydrogen is produced by photolysis of water vapor, a reliable determination of the $H / D$ ratio would provide important information on the history of water on Venus.

The day and night ionization profiles determined by the Mariner Stanford Group (Figure 10) provide indirect evidence for abundant $\mathrm{He}^{4}$. The day time densities of $10^{4}$ electrons $\mathrm{cm}^{-3}$ near 200 and $500 \mathrm{~km}$ can be easily explained by ionization of $\mathrm{He}^{4}$, provided that the $\mathrm{He}^{4}$ abundance at $200 \mathrm{~km}$ is near $5 \times 10^{7} \mathrm{~cm}^{-3}$. This ionization cannot be easily accounted for by combinations of other likely constituents such as $\mathrm{CO}_{2}, \mathrm{H}, \mathrm{D}$, or $\mathrm{H}_{2}$ (Whitten 1970). Concentrations of $\mathrm{He}^{4}$ of this magnitude have also been inferred by McElroy \& Strobel (1969) as a plausible source for the observed night-side ionosphere. The latter could be maintained by transport of helium ions from the dayside by $100-200 \mathrm{~m} / \mathrm{s}$ winds above $200 \mathrm{~km}$. Knudsen \& Anderson (1969) argue that the $\mathrm{He}^{4}$ abundance of $5 \times 10^{7} \mathrm{~cm}^{-3}$ at the $200 \mathrm{~km}$ level on Venus implies that the rate of radiogenic production and outgassing of $\mathrm{He}^{4}$ on Venus is at least as large as the terrestrial rate.

\section{Atmospheric Drnamics}

The large-scale dynamics of planetary atmospheres reflect a balance between the rate of generation of potential energy by radiation and the rate of destruction of mechanical energy by dissipation. Heat enters the system in the sunlit hemisphere and leaves the system from both hemispheres. An attempt to derive the scaling of velocity amplitudes and temperature differences from one planet to another was made by Golytsin (1970). He finds that the amplitude of the motion varies inversely as the mass of the atmosphere and directly as the solar heating. His theory does not account for the organization and direction of the motion, or for the occasional concentration of activity into intense local phenomena, such as dust devils on Mars, nor does it account for rapid rotation of part of the Venus atmosphere which we discuss below.

Venus lower-atmosphere dynamics.-Goody (1969) has summarized the- 
ories of the deep atmospheric circulation of Venus (Goody \& Robinson 1966, IIess 1968, Stone 1968). The essential feature of these models is that there is no rotation of the atmosphere or the planet. The motion consists of a single overturning cell, symmetric about the subsolar and antisolar points, with rising motion at the subsolar point and sinking motion at the antisolar point. These models offer one explanation for the relatively small temperature contrast over the Venus clouds (Figure 8) and for the adiabatic temperature distribution in the deep atmosphere.

Goody's (1969) review contains only a brief discussion of the observations which suggest that near the tops of the Venus clouds, the atmosphere rotates with a 4 day period. The solid planet rotates with a 243 day period, and both rotations are retrograde, that is, opposite to the direction of orbital motion. The first evidence for the 4 day rotation came in photographs taken through an ultraviolet filter (wavelength $3500-4000 \AA$ ). At these wavelengths, amorphous patches of light and dark are detectable, and their motion can be measured by comparing photographs taken several hours apart (Smith 1967, Dollfus 1968, Boyer \& Guérin 1969). Figure 14 shows one such sequence. Guinot \& Feissel (1968) claim to have measured this motion spectroscopically. Ingersoll (1970b) has shown how the stratospheric oblateness associated with this motion could be detected with radio occultation data.

Schubert \& Whitehead (1969) were the first to suggest that the 4 day circulation is the atmosphere's rectified response to the periodic thermal forcing of the Sun. This model was further elaborated by Schubert \& Young (1970), Thompson (1970), and Malkus (1970). The only model which considers radiative heat transfer in a realistic way is Gierasch's (1970) model, which we will describe here. Gierasch assumes that heat is deposited as sun-

\section{VENUS ON 2I-22 MAY 1967}
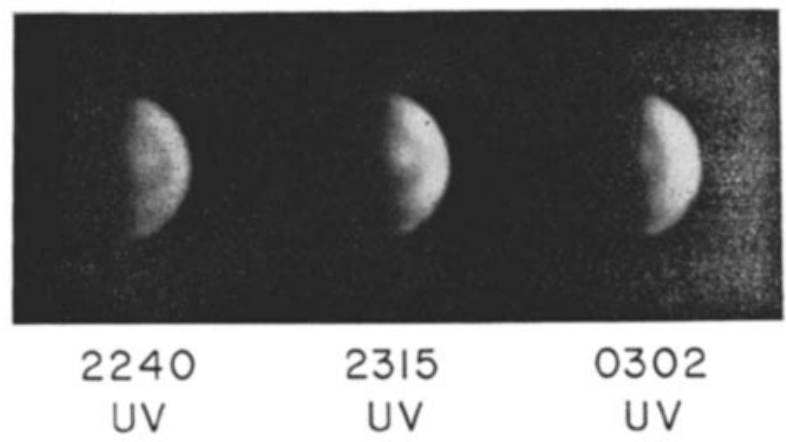

FIGURE 14. Ultraviolet photographs of Venus on 21-22 May 1967. Note the right to left (retrograde) drift of the dark circular marking during the $4.4 \mathrm{hr}$ interval. Courtesy of the New. Mexico State University Observatory. 


\section{2}

light at some level within the cloud, where the atmosphere is presumed to rotate with the solid planet. Thus, the stratosphere above the cloud is warmed by radiation from below which varies periodically at the overhead frequency of the Sun. The radiative adjustment time of the stratosphere decreases as height increases, however, so the rotation of the stratosphere must increase with height in order that there be no phase shift in the thermal wave. If the phase of the wave were to vary with height, thermally driven motions would act to restore constant phase. Radiative adjustment times for $\mathrm{CO}_{2}$ are known (Goody \& Belton 1967), and with these Gierasch is able to compute the speed of the stratosphere as a function of height. He finds that the period is 4 days at the $P=40 \mathrm{mb}$ level.

The Venus atmosphere may also play an important part in the dynamics of the planet's rotation. Gold \& Soter (1969) showed that the effect of the thermal tide on Venus, if it were as large as the thermal tide on the Earth, might cancel the effect of the solid-body tide which tends to bring the planet into a prograde synchronous rotation. Ingersoll \& Hinch (1971) have attempted to compute the atmospheric tide directly, and they find that the resulting torque is of the right order of magnitude to balance the solid-body torque. For their model to be valid, the lapse rate must be very close to the adiabatic lapse rate, but this is not an unwarranted assumption, according to recent occultation data (Figure 6).

Mars lower-atmosphere dynamics.--Similarities in rotation rates, axial tilts, and the small optical thicknesses for solar radiation for the Earth and Mars suggest that similar kinds of circulation are to be expected on the two planets (Leovy 1969). A major difference arises in the response of the surface temperature to seasonal changes. On the Earth, the oceans tend to maintain the average surface temperature in any latitude belt close to its annual average, and the atmosphere tends to distribute heat evenly with respect to latitude. On Mars, the thermal inertia of the ground and the heat capacity of the atmosphere are both small, and the surface temperature tends to be close to its local radiative equilibrium value at each latitude. Other differences include: the shorter radiative adjustment time for temperature perturbations (Goody \& Belton 1967), absence of energetically significant latent heat effects due to water vapor on Mars, and the existence of very largeamplitude, large-scale Mars topography (Pettingill et al 1969, Belton \& Hunten 1969b).

Atmospheric wind systems are driven by the uneven distribution, in time and space, of the solar heating. The dynamical behavior of large-scale wind systems depends on whether the thermal driving mechanism has a period longer or shorter than the planet's rotation period. On the Earth, the mean latitudinal difference in temperature drives the mean zonal (east-west) winds at midlatitudes, as well as the large cyclones and anticyclones which convect heat poleward. Such systems are expected on Mars, but because latitudinal temperature differences are larger than on Earth, larger velocities 
are expected. On the Earth, large-scale wind systems associated with diurnal temperature differences are relatively weak, because the diurnal thermal response of the atmosphere is small. On Mars, where diurnal temperature changes are larger, the associated diurnal wind systems are also expected to be larger.

Computer simulations of large-scale Mars wind systems have been carried out by Leovy \& Mintz (1969). They used finite-difference analogues of the fluid mechanical equations to derive time-dependent temperatures and wind profiles on a coarse grid ( $15^{\circ}$ longitude by $7^{\circ}$ latitude) at two levels, at approximately 3 and $13 \mathrm{~km}$ heights. Some time-averaged temperature values obtained from these simulations are compared with temperatures inferred from the Mariner S-band occultation data, and with temperatures computed by Gierasch \& Goody in Figure 7. The agreement is reasonably good, considering the many uncertainties in the theories and in the interpretation of the occultation data. Figure 15 shows the zonally averaged zonal and meridional winds computed by Leovy \& Mintz. Their model also predicts large-scale cyclonic disturbances in all seasons except summer, and significant diurnal and semidiurnal wind oscillations. The diurnal heating, which is responsible for these "thermal tides," and the nature of the resulting oscillation have also been discussed by Gierasch \& Goody (1968), Leovy (1969), and Lindzen (1970). The analogous problem for the Earth has been described in a recent monograph by Chapman \& Lindzen (1970).

A recent systematic study of bright objects suspected of being clouds in the Lowell Observatory collection of Mars plates (5000 plates dating back to 1907) by Martin \& Baum (1969) revealed only a few moving features, and predominantly low speeds $(<5 \mathrm{~m} / \mathrm{s})$ for most of these. Since high winds are expected, we infer that most of the features scen by Martin and Baum either were not clouds, or if clouds, were fixed to local surface features in the same way that wave clouds on the Earth remain stationary in flow over mountains.

The topography of Mars must exert a strong influence on the circulation. A partial theory of motions driven by large-scale topography, as observed over the Great Plains, has been given by Holton (1967). Gierasch \& Sagan (1971) have pointed out that such topography can substantially intensify thermally driven winds on Mars.

Upper-atmosphere circulation and mixing.-Comparatively little work has been done on possible circulations of the upper atmospheres of Mars and Venus, even though, as we have seen, the validity of inferences drawn from static models depends partly on the degree to which circulation maintains local conditions in the thermosphere close to global average conditions. Dickinson (1969) has presented analytical and numerical solutions for flow in the thermosphere of a nonrotating planet. His solutions may be applicable to Venus. The results show that horizontal winds $\sim 100-200 \mathrm{~m} / \mathrm{s}$ are to be expected and are capable of maintaining a fair degree of temperature equilization between day and night sides (Dickinson 1970). These wind speeds are 

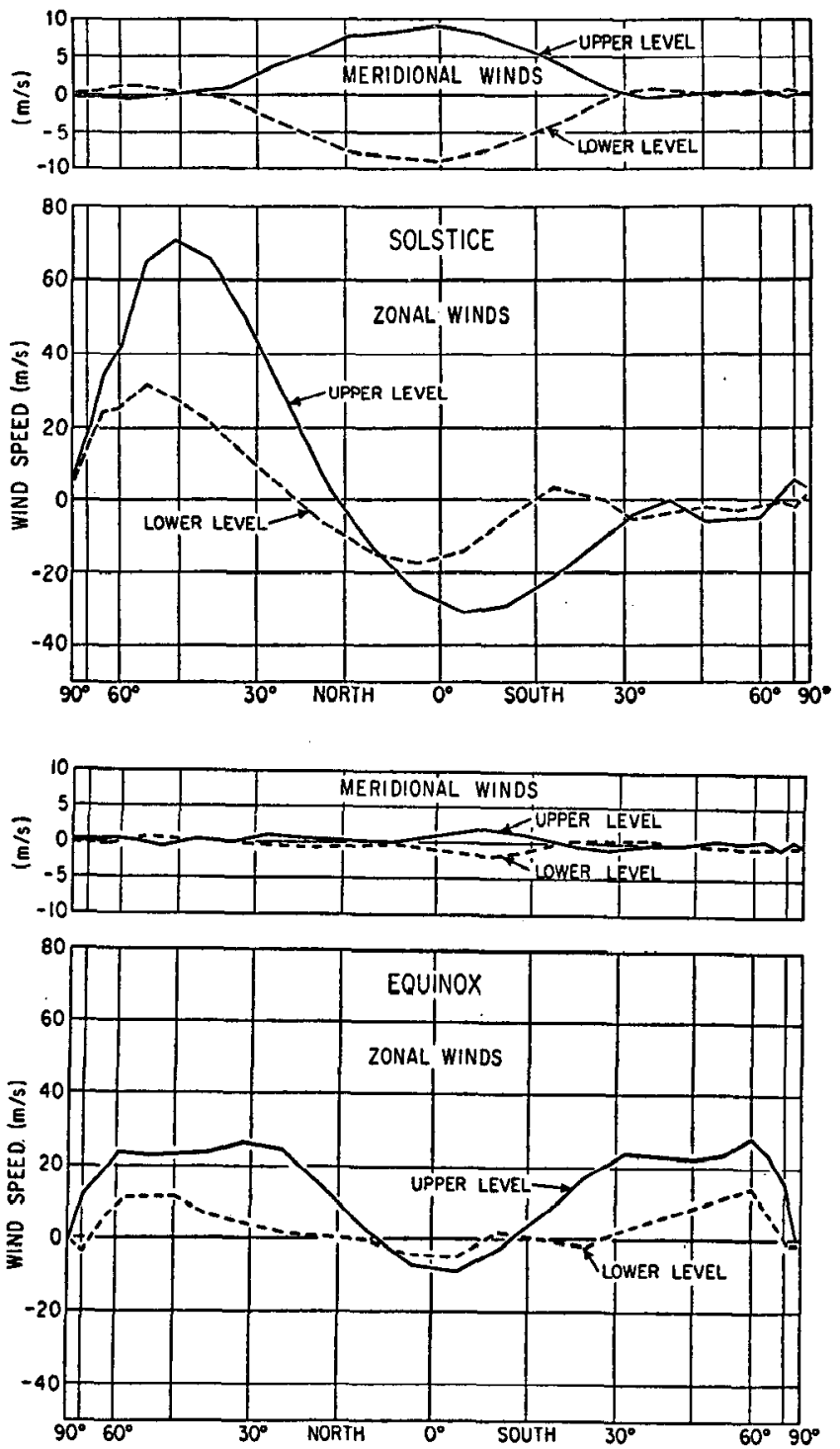

FIGURE 15. Zonally averaged zonal and meridional winds for Mars at two levels: approximately 3 and $13 \mathrm{~km}$. Zonal winds are reckoned positive from the west, meridional winds positive from the south. Reproduced by permission of the American Meteorological Society from Leovy \& Mintz (1969). 
comparable to those required by McElroy \& Strobel (1969) to account for Venus' nightside ionosphere.

We have seen that the intensity of vertical mixing by turbulent eddies is a key to the understanding of several aeronomic problems: Why does $\mathrm{CO}_{2}$ remain undissociated in the upper atmospheres? What is the $\mathrm{D} / \mathrm{H}$ ratio on Venus? What is the $\mathrm{N}_{2}$ concentration on Mars? Lindzen (1970) speculates that the vertically propagating diurnal tide provides a major mechanism for generating turbulence and mixing in the Earth's upper atmosphere at latitudes between $\pm 30^{\circ}$. He extends this reasoning to Mars to suggest that the region of turbulent mixing would extend $14 \pm 1$ scale heights above the surface (about $100 \mathrm{~km}$ ). Lindzen also estimates that if the vertical energy transported upward by the terrestrial semidiurnal tide is dissipated in the thermosphere, it would maintain the thermosphere at $600^{\circ} \mathrm{K}$ without any other heating mechanism. Evidently possible dissipative heating of the Mars thermosphere by tides must be seriously considered. Other types of largescale tropospheric disturbances may also propagate energy upward (Matsuno 1970), but our understanding of their role in upper-atmosphere phenomena is still rudimentary.

\section{Evolution of THE ATMOSPheres}

Studying the atmospheres of the terrestrial planets provides information which is essential in our understanding of the Earth's atmosphere and its history. Clearly the composition of a planetary atmosphere is determined by several factors, including the mass and composition of the solid planet, the amount of incident sunlight, and conditions at the time of planetary formation. One of the most intriguing questions is whether the Earth is unique, or whether it is simply a member of the series of terrestrial planets, somehow filling the gap between Venus and Mars. We would like to know, for instance: to what extent do the outgassing histories of the terrestrial planets differ and to what extent have their atmospheres been modified after outgassing?

Reactions between atmosphere and crust.-We mentioned in the introduction that most of the Earth's $\mathrm{CO}_{2}$ which has been released from the interior is now buried in sedimentary rocks (Table 1). The concentration of $\mathrm{CO}_{2}$ in the oceans, and therefore the $\mathrm{CO}_{2}$ partial pressure in the atmosphere, is set by reactions of the form

$$
\mathrm{CaSiO}_{3}+\mathrm{CO}_{2} \rightleftharpoons \mathrm{CaCO}_{3}+\mathrm{SiO}_{2}
$$

Such reactions are at equilibrium in shallow seas where carbonate sediments are being deposited (Rubey 1951).

Mueller (1964) pointed out that reactions between $\mathrm{CO}_{2}$ and common silicates might also set the $\mathrm{CO}_{2}$ partial pressure on Venus. Lewis (1968) attempted to locate the Venus surface by computing the intersection of the observed pressure-temperature curve of the atmosphere and the equilibrium pressure-temperature curve of the relevant chemical reactions. Difficulties 
arise because there are several different reactions, involving different silicate compounds, and any of them might determine the equilibrium point. In any case, it is possible that there are extensive carbonate deposits on Venus, and that the amount of $\mathrm{CO}_{2}$ released by outgassing is greater than the amount observed in the atmosphere today.

Lewis $(1969,1970)$ has also considered the chemistry of other volatile elements on Venus; his choice of elements is based mainly on terrestrial and solar abundances. He argues that because of the high surface temperatures, a large number of compounds may be present in the atmosphere in detectable quantities. Besides $\mathrm{H}_{2} \mathrm{O}, \mathrm{CO}, \mathrm{HCl}$, and $\mathrm{HF}$, which have already been detected, he adds $\mathrm{COS}, \mathrm{H}_{2} \mathrm{~S}, \mathrm{NH}_{3}, \mathrm{HBr}, \mathrm{Hg}, \mathrm{HgBr}_{2}$, and many others. He has proposed several of these as likely constituents of the Venus clouds. As we have seen, there is some evidence for a multilayered cloud structure (Fjeldbo, Kliore \& Eshleman 1971, Rasool 1970), but no further evidence that Lewis' model is correct.

The other important volatile on Venus is water. Mueller (1964) feels that the water vapor abundance is set by a balance between the rate of outgassing and the rate of photodissociation and escape. This is also the point of view taken by Walker, Turekian \& Hunten (1970). Lewis (1968) claims that water may be in equilibrium with surface rocks, which raises the possibility that vast amounts of water are locked up chemically at the surface. Others (Fricker \& Reynolds 1968, Anders 1968) have proposed that the amount of water outgassed from the interior is a small quantity, essentially equal to the present-day atmospheric abundance. The other possibility, that large amounts of water (equivalent to the Earth's oceans) have been lost on Venus, will be discussed later.

On Mars, both $\mathrm{H}_{2} \mathrm{O}$ and $\mathrm{CO}_{2}$ occur in solid and vapor form, so that it is impossible to estimate the amounts outgassed from atmospheric abundances alone. However, the upper limit to the amount of $\mathrm{N}_{2}$ is about $0.3 \mathrm{mb}$ (Dalgarno \& McElroy 1970), which implies either that the amount of outgassing on Mars is $10^{-3}$ that of the Earth, or that nitrogen is bound chemically at the surface of Mars. The upper limit $\mathrm{N}_{2} / \mathrm{CO}_{2}<5 \%$ in the Mars atmosphere is roughly equal to the ratio $\mathrm{N}_{2} / \mathrm{CO}_{2}$ for the Earth's volatiles (Table 1). However, if the amount of solid $\mathrm{CO}_{2}$ in the Mars polar caps is much greater than the amount in the atmosphere, then the ratio of $\mathrm{N}_{2}$ to $\mathrm{CO}_{2}$ outgassed on Mars might be less than that outgassed on the Earth. The upper limit to the ratio of $\mathrm{N}_{2}$ to $\mathrm{CO}_{2}$ on Venus is also about $5 \%$, and similar remarks apply. A positive detection of $\mathrm{N}_{2}$ on either Mars or Venus would be an important aid to understanding the outgassing histories of the terrestrial planets.

Escape of atmospheric gases.-A classic description of escape by thermal acceleration of molecules at the top of an atmosphere was given by Spitzer (1952). The escape flux depends on the ratio of the planetary escape velocity to the mean thermal velocity of molecules in the exosphere. If the temperature of the neutral atmosphere and the density of each component are known 
at the base of the exosphere, the escape flux can be computed. Where direct measurements are not available, the escape flux may be computed from theoretical models of the upper atmosphere.

For the lightest gas, hydrogen, the probability of escape is so great that the actual escape flux usually depends on the rate of supply from levels below the exosphere. On the Earth, hydrogen is produced mainly by photodissociation of water vapor near the mesopause (Berkner \& Marshall 1965, Brinkmann 1969). An important question is whether photodissociation of water and escape of hydrogen could have accounted for the initial accumulation of oxygen in the Earth's atmosphere. It is clear; from the oxidation state of gases in equilibrium with basaltic melts, that oxygen could not have been released directly in to the atmosphere by outgassing (Holland 1964). Berkner \& Marshall (1965) claim that the amount of oxygen in the Earth's atmosphere began to rise rapidly as a result of photosynthetic activity by green plants. But Brinkmann (1969) has shown that the rate of photodissociation of water and escape of hydrogen may have been sufficient to account for the early rise of oxygen in the absence of biological activity. The question has important implications for theories of the origin of life.

Walker, Turekian \& Hunten (1970) deduce an upper limit to the escape of hydrogen from Venus, based on Mariner 5 Ly $\alpha$ observations (Figure 11). They assume that the escape flux is controlled by the rate of photodissociation of water in the Venus atmosphere; from the inferred upper limit to the escape flux they compute the maximum rate of supply of water from the interior. The rate of supply is 5 orders of magnitude less than the rate needed to supply an amount of water equivalent to the Earth's oceans during $4.5 \times 10^{9}$ years. Then, assuming that the outgassing histories of the Earth and Venus are the same, they conclude that the rate of supply was much greater in the past than it is at present on both planets.

A major difficulty with the assumption that the outgassing histories of the Earth and Venus are the same is that Venus probably has no more than $10^{-3}$ the amount of water that the Earth has. (Here we are assuming that large amounts of water are not locked up in crustal rocks on Venus.) Many authors (Hoyle 1955, Sagan 1960, Gold 1964, Shimazu \& Urabe 1968, Ingersoll 1969, Rasool \& de Bergh 1970) have discussed the possibility that this difference is due to the different escape histories of Venus and the Earth. The hypothesis to be tested is that water was once abundant on both planets and that the rate of photodissociation of water on Venus was then 3 or 4 orders of magnitude greater than it is on the Earth at present. If an ocean of water were added to Venus today, it is likely that water vapor would be a major atmospheric constituent. It can also be shown that if the present Earth were moved to the orbit of Venus, water vapor might soon become the major atmospheric constituent. Several authors (Sagan 1960, Gold 1964, Donahue 1968) argued that this would not significantly increase the rate of photodissociation of water, because water would still be a trace constituent at the high altitudes where photodissociation takes place. Later, Sagan 
(1968) and Jastrow \& Rasool (1969) argued that the fraction of water vapor in the stratosphere would have been large enough to permit rapid photodissociation, provided the stratospheric temperature were sufficiently large. However, Ingersoll (1969) showed that, regardless of the stratospheric temperature, water vapor would be a major constituent at all atmospheric levels if it were a major constituent at the surface. In short, it appears possible that the rate of photodissociation of water on Venus was once 3 or 4 orders of magnitude greater than it is on the Earth today.

If Venus has lost its oceans in this way, the amount of hydrogen which has escaped is large. Since deuterium escapes more slowly than ordinary hydrogen, the ratio $\mathrm{D} / \mathrm{H}$ would be larger on Venus than it is on the Earth. As we have seen, there is some evidence, based on the Ly $\alpha$ emission near Venus, that this is the case (Donahue 1969, McElroy \& Hunten 1969, Wallace 1969). The absence of free oxygen is then a mystery. If the primary gases from the interior of Venus were $\mathrm{H}_{2} \mathrm{O}, \mathrm{CH}_{4}$, and $\mathrm{CO}$, in relative abundances such that the elemental ratio $\mathrm{O} / \mathrm{C}$ were less than 2 , then only $\mathrm{CO}_{2}, \mathrm{CO}$, and/or $\mathrm{C}$ would remain. However, for the Earth's volatiles, the elemental ratio $\mathrm{O} / \mathrm{C}$ is greater than 2 . Another alternative is that ferrous iron in the crust of Venus has been oxidized to a depth of $\sim 10 \mathrm{~km}$, sufficient to accommodate the liberated oxygen. No definitive test of these hypotheses has been proposed.

McElroy \& Hunten (1970) have estimated the rate of photodissociation of water on Mars. They claim that at the present rate several meters of precipitable water might have been lost in $4.5 \times 10^{9}$ years. This is equivalent to a partial pressure at the surface of about $100 \mathrm{mb}$, or 20 times the mass of $\mathrm{CO}_{2}$ observed in the atmosphere.

The escape of $\mathrm{CO}_{2}$ and other gases from Mercury was analyzed by Rasool, Gross \& McGovern (1966). Since their review, there has been a considerable increase in understanding of upper atmospheres in which $\mathrm{CO}_{2}$ is a major constituent. Perhaps the subject should be reexamined. If the terrestrial planets are indeed closely related, the absence of an atmosphere on Mercury may prove to be the most puzzling observation of all.

\section{ACKNOWLEDGMENT}

We should like to thank Drs. Peter Goldreich, Duane O. Muhleman, and Carl Sagan for offering useful comments and suggestions. The participation of A. P. Ingersoll was supported in part under NASA grant NGL 05-002-003, and the participation of $C$. B. Leovy was supported in part under NASA grant 48-002-073. 


\section{LITERATURE CITED}

Abhyankar, K, D, 1968, Icarus 9:507

Anders, E. 1968. Accounts Chem. Res. 1: 289

Arking, A., Potter, J. 1968. J. Atm. Sci. 25:617

Ash, M. E. et al 1968. J. Atm. Sci. 25:560

Avduevsky, V. S., Marov, M. Ya., Noykina, A. I., Polezhaev, V. I., Zavelevich, F. S. 1970. J. Atm. S ci. 27:569

Avduevsky, V. S., Marov, M. Ya., Rozhdestvensky, M. K. 1970. J. Atm. Sci. 27:561

Avduevsky, V. S., Marov, M. Ya., Rozhdestvensky, M. K., Borodin, N. F., Kerzhanovich, V. V. 1971. To be published

Barth, C. A. 1968. J. Atm. Sci. 25:564

Barth, C. A. 1969. Appl. Opt. 8:1259

Barth, C. A., Hord, C. W. 1971. To be published

Barth, C. A., Pearce, J. B., Kelley, K. K., Wallace, L., Fastie, G. 1967. Science 158:1675

Barth, C, A., Wallace, L., Pearce, J. B. 1968. J. Geophys. Res. 73:2541

Barth, C. A. et al 1969. Science $165: 1004$

Belton, M. J. S. 1968. J. Atm. Sci. 25:596

Belton, M. J. S., Hunten, D. M. 1966. Ap. J. 146:307

Belton, M. J. S., Hunten, D. M. 1968. Ap. J. 153:963

Belton, M. J. S., Hunten, D. M. 1969a. Ap. J. 156:797

Belton, M. J. S., Hunten, D. M. 1969b. Science 166:225

Belton, M. J. S., Hunten, D. M., Goody, R. M. 1968. The Atmospheres of Venus and Mars, ed. J. C. Brandt, M. B. McElroy, 69. New York: Gordon \& Breach

Belton, M. J. S., Hunten, D. M., McElroy, M. B. 1967. Ap. J. 150:1111

Bergstralh, J. T., Gray, L. D., Smith, H. J. 1967. Ap. J. 149:L137

Berkner, L. V., Marshall, L. C. 1965. J. Atm. Sci. 22:225

Bottema, M., Plummer, W., Strong, J. 1965. Ap.J. 140:1640

Bottema, M., Plummer, W., Strong; J., Zander, R. 1965. J. Geophys. Res. 70: 4401

Boyer, C., Guérin, P. 1969. Icarus 11:338

Brancazio, P. J., Cameron, A. G. W., Eds. 1964. The Origin and Evolution of Atmospheres and Oceans. New York: Wiley

Brandt, J. C., McElroy, M. B., Eds. 1968.
The Atmospheres of Venus and Mars. New York: Gordon \& Breach

Brinkmann, R. T. 1969. J. Geophys. Res. $74: 5355$

Brown, H. 1952, The Atmospheres of the Earth and Planets, ed. G. P. Kuiper, 258. Chicago: Univ. Chicago Press. 2nd ed.

Capen, C. F. 1970. Icarus 12:118

Carleton, N. P., Sharma, A., Goody, R. M., Liller, W. Roesler, F. L. 1969. Ap. J. 155:323

Chamberlain, J. W. 1965. Ap. J. 141:1184

Chapman, S., Lindzen, R. S. 1970. Atmaspheric Tides. Dordrecht, Holland: Reidel

Clark, I. D., Noxon, J. F. 1970. J. Geophys. Res, $75: 7307$

Cloutier, P. A., McElroy, M. B., Michel, F. C. 1969. J. Geophys. Res. 74:6216

Clyne, M., Thrush, B. A. 1962. Proc. Roy. Soc. London A 269:404

Coffeen, D. L. 1969. Astron. J. $74: 446$

Connes, P., Connes, J., Benedict, W. S., Kaplan, L. D. 1967. Ap. J. 147:1230

Connes, P., Connes, J., Kaplan, L. D., Benedict, W. S. 1968. Ap. J. 152:731

Dalgarno, A., McElroy, M. B. 1970. Science 170:167

De More, W. B. 1970. J. Geophys. Res. $75: 4898$

de Vaucouleurs, G. 1968. Icarus 9:598

de Vaucouleur's, G., Menzel, D. H. 1960. Nature 188:28

de Wolf, D. A. 1970. J. Geophys. Res. $75: 1202$

Dickel, J. R. 1967. Icarus 6:417

Dickinson, R. 1969. J. Atm. Sci. 26:1199

Dickinson, R. 1970. Eos $51: 766$

Dollfus, A. 1961. Planets and Satellites, ed. G. P. Kuiper, B. M. Middlehurst, 534. Chicago: Univ. Chicago Press

Dollfus, A. 1963. C. R. Acad. Sci., 256: 3250

Dollfus, A. 1968. The Atmospheres of Venus and Mars, ed. J. C. Brandt, M. E. McElroy, 133. New York: Gordon \& Breach

Dollfus, A., Focas, J. H. 1969. Astron. Ap. $2: 63$

Donahue, T. M. 1968. J. Atm. Sci. 25:568

Donahue, T. M. 1969. J. Geophys. Res. $74: 1128$

Eshleman, V. R. 1970. Radio Sci. 5:325

Eshleman, V. R., et al 1968. Science 162: 661

Felder, W., Morrow, W., Young, R. A. 1970, J, Geophys. Res, 75:7311-15 
Fjeldbo, G., Eshleman, V. R. 1968. Planet. Space Sci. 16:1035

Fjeldbo, G., Kliore, A., Eshleman, V. R. 1971. To be published, Astron. J.

Fjeldbo, G., Kliore, A., Seidel, B. 1970. Radio Sci. $5: 381$

Fricker, P. E., Reynolds, R. T. 1968. Icarus 9:221

Gale, W., Liwshitz, M., Sinclair, A. C. E. 1969. Science 164:1059

Gale, W., Sinclair, A. C. E. 1969. Science $165: 1356$

Gierasch, P. J. 1970. Icarus 13:25

Gierasch, P. J. 1971. To be published, $J$. Alm. Sci.

Gierasch, P. J., Goody, R. M. 1968. Planet Space Sci. 16:615

Gierasch, P. J., Goody, R. M. 1970. J. Atm. Sci. 27:224

Gierasch, P. J., Sagan, C. 1971. To be published, Icarus

Gillett, F. C., Low, F. J., Stein, W. A. 1968. J. Atm. Sci. 25:594

Giver, L. P., Inn, E. C. Y., Miller, J. H., Boese, R. W. 1968. Ap. J. 153:285

Gold, T. 1964. The Origin and Evolution of Atmospheres and Oceans, ed. P. J. Brancazio, A. G. W. Cameron, 249. New York: Wiley

Gold, T., Soter, S. 1969. Icarus: 11:356

Goldstein, R. M. et al 1970. Radio Sci. $5: 475$

Golytsin, G. H. 1970. Icarus 13:1

Goody, R. M. 1967. Planet Space Sci. 15: 1817

Goody, R. M. 1969. Ann. Rev. Astron. Ap. $7: 303$

Goody, R. M., Belton, M. J. S, 1967. Planet. Space Sci. 15:247

Goody, R. M., Robinson, A. R. 1966. Ap. J. $146: 339$

Gross, S. H., McGovern, W. E., Rasool, S. I. 1968. The Atmospheres of Venus and Mars, ed. J. C. Brandt, M. B. McElroy, 103. New York: Gordon \& Breach

Guinot, B., Feissel, M. 1968. Publ. Obs. Haute-Provence 9:No. 361

Hanel, R., Forman, M., Stambach, G., Meilleur, T. 1968. J. Atm. Sci. $25: 586$

Hansen, J. E., Arking, A. 1971. Science 171: 669

Hansen, J. E., Cheyney, H. 1968. J. Atm. Sci. 25:629

Hansen, J. E., Matsushima, S. 1967. Ap. J. 150:1139

Henry, R. W., McElroy, M. B. 1968. The Atmospheres of Venus and Mars, ed. J. C. Brandt, M. B. McElroy, 251. New York: Gordon \& Breach

Herr, K. C., Pimentel, G. C. 1969. Science $166: 496$

Herr, K. C., Pimentel, G. C. 1970. Science $167: 47$
Hess, S. L. 1968. The Atmospheres of Venus and Mars, ed. J. C. Brandt, M. B. McElroy, 109. New York: Gordon \& Breach

Hogan, J. S., Stewart, R. W. 1969. J. Atm. Sci. 26:322

Holland, H. D. 1964. The Orgin and Evolution of Atmospheres and Oceans, ed. P. J. Brancazio, A. G. W. Cameron, 86. New York: Wiley

Holton, J. R. 1967. Tellus 19:199

Hoyle, F. 1955. Frontiers in Astronomy, 68. London: William Heinemann

Hunten, D. M., McElroy, M. B. 1968. $J$. Geophys. Res, 73:4446

Hunten, D. M., Goody, R. M. 1969. Science $165: 1317$

Ingersoll, A. P. 1969. J. Atm. Sci. 26:1191

Ingersoll, A. P. 1970a. Science 169:972

Ingersoll, A. P. 1970b. Icarus 13:34

Ingersoll, A. P. 1971. A p. J. 163:121

Ingersoll, A. P., Hinch, E. J. 1971. To be published

Irvine, W. M. 1968. J. Atm. Sci. 25:610

Jastrow, R. 1968. Science 160:1403

Jastrow, R., Rasool, S. I. 1969. The Venus Atmosphere, 1. New York: Gordon \& Breach

Kaplan, L. D., Connes, J., Connes, P. 1969. Ap. J. 157:L187

Kaplan, L. D., Munch, G., Spinrad, H. 1964. Ap. J. 139:1

Kieffer, H. 1970a. J. Geophys, Res. 75:501

Kieffer, H. 1970b. J. Geophys, Res. 75:510

Kliore, A., Cain, D. L. 1968. J. Atm. Sci. $25: 549$

Kliore, A., Levy, G. S., Cain, D. L., Fjeldbo, G., Rasool, S. 1967. Science 158:1683

Kliore, A., Cain, D., Fjeldbo, G., Rasool, S. I. 1969a. Space Research IX. Amsterdam: North-Holland

Kliore, A., Fjeldbo, G., Seidel, B. L., Rasool, S. I. 1969b. Science 166:1393

Knudsen, W. C., Anderson, A. D. 1969. J. Geophys. Res. 74:5629

Kurt, V. G., Dostolow, S. B., Sheffer, E. K. 1968. J. Atm. Sci. $25: 668$

Kuiper, G. P. 1969a. Comm. Lunar Planet. Lab. 100:209

Kuiper, G. P. 1969b. Comm. Lunar Planet. Lab. 101:229

Leighton, R. B., Murray, B. C. 1966. Science 153:136

Leighton, R. B. et al 1969. Science 166:49

Leovy, C. 1969. Appl. Opi. 8:1279

Leovy, C., Mintz, Y. 1969. J. Atm. Sci. 26:1167

Leovy, C. B., Smith, B. A., Young, A. T., Leighton, R. B. 1971.J. Geophys. Res. $76: 297$

Lewis, J. S. 1968. Icarus 8:434

Lewis, J. S. 1969. Icarus 11:367 


\section{ATMOSPHERES OF MARS AND VENUS}

Lewis, J. S. 1970. Radio Sci. 5:363

Lindzen, R. S. 1970. J. Atm. Sci. 27:537

Malkus, W. V. R. 1970. J. Atm.Sci. 27:529

Mariner Stanford Group 1967. Science 158:1678

Martin, W. L., Baum, W. A. 1969. A Study of Cloud Motions on Mars. Flagstaff, Ariz: Planet. Res. Cent., Lowell Obs.

Matsuno, T. 1970. J. Alm. Sci. 27:871

McConnell, J. C., McElroy, M. B. 1970. J. Geophys, Res. 75:7290

McCord, T. B. 1969. Ap. J. 156:79

McCord, T. B., Westphal, J. A. 1971. To be published, $A p . J$.

McElroy, M. B. 1967. Ap. J. 150:1125

McElroy, M. B. 1969. J. Geophys. Res. $74: 29$

McElroy, M. B., Hunten, D. M. 1969. J. Geophys. Res. 74:1720

McElroy, M. B., Hunten, D. M. 1970. J. Geophys. Res. $75: 1188$

McElroy, M. B., Strobel, D. F. 1969. $J$. Geophys. Res. 74:1118

Melbourne, W. G., Muhleman, D. O., O'Handley, D. A. 1968. Science 160:987

Moos, H. W., Fastie, W. G., Bottema, M. 1969. Ap. J. 155:887

Moroz, V. I. 1965. Sov. Astron.-AJ 8:566

Moroz, V. I. 1968. Sov. Astron.-AJ 11:653

Morozhenko, A. V. 1970. Sov. Astron.-AJ 13:852

Morrison, D. 1970. To be published

Morrison, D., Sagan, C. 1967. Ap. J. 150: 1105

Mueller, R. F. 1964. Icarus 3:285

Muhleman, D. O. 1969. Astron. J. 74:57

Murdock, T. L., Ney, E. P. 1970. Science 170:535

Murray, B. C., Wildey, R. L., Westphal, J. A. 1963. J. Geophys. Res. 68:4813

Neugebauer, G. et al 1969. Science 166:98

Ohring, G. 1969. Icarus 11:171

O'Leary, B. T. 1967. Ap.J. 149:L147

O'Leary, B. T., Rea, D. G. 1967. Ap. $J$. 148:249

Pettengill, G. H., Councilman, C. C., Rainville, L. P., Shapiro, I. I. 1969. Astron. J. $74: 461$

Plass, G. N., Stull, V: R. 1963. J. Geophys. Res. 68:1355

Plummer, W. T. 1970. Icarus $12: 233$

Pollack, J. B. 1969. Icarus 10:314

Pollack, J. B., Morrison, D. 1970. Icarus $12: 376$

Pollack, J. B., Sagan, C. 1968. J. Geophys. Res. 73:5943

Pollack, J. B., Sagan, C. 1969. Space Sci. Rev. 9:243

Pollack, J. B., Sagan, C. 1970. Radio Sci. $5: 443$

Pollack, J. B., Pitman, D., Khare, B. N., Sagan, C. 1970. J. Geophys. Res. 75: 7480
Rasool, S. I. 1970. Radio Sci. 5:367

Rasool, S. I., de Bergh, C. 1970. Nature 226:1037

Rasool, S. I., Gross, S. H., McGovern, W. E. 1966. Space Sci. Rev. 5:565

Rasool, S. I., Hogan, J. S., Stewart, R. W., Russell, L. H. 1970. J. Atm. Sci. 27:841

Rea, D. G., O'Leary, B. T. 1968.J. Geophys. Res. 73:665

Ronov, A. B., Yaroshevsky, A. A. 1967. Geochim. Int. 4:1041

Rubey, W. W. 1951. Bull. Geol. Soc. Am. $62: 1111$

Sagan, C. 1960. The Radiation Balance of Venus. Tech. Rep. 32-34. JPL, Calif. Inst. Technol.

Sagan, C. 1966. Ap. J. 144:1218

Sagan, C. 1968. International Dictionary of Geophysics, ed. S. K. Runcorn, 2049. London: Pergamon

Sagan, C., Kellogg, W. W. 1963. Ann. Rev. Astron. Ap. 1:235

Sagan, C., Owen, T., Smith, H. 1971. Proc. IAU Symp. 40 Planetary Almospheres. Dordrecht, Holland: Reidel

Samuelson, R. E. 1967. Ap. J. 147:782

Samuelson, R. E. 1968. J. Atm. Sci. 25:634

Schilling, G. F., Moore, R. C. 1967. The Twilight Atmosphere of Venus. Memo. $R M-5386-P R$. Santa Monica, Calif: RAND Corp.

Schorn, R. A., Barker, E. S., Gray, L. D., Moore, R. C. 1969. Icarus 10:98

Schorn, R. A., Farmer, C. B., Little, S. J. 1969. Icarus 11:283

Schubert, G., Whitehead, J. 1969. Science 163:71

Schubert, G., Young, R. E. 1970. J. Atm. Sci. 27:523

Shimazu, Y., Urabe, T. 1968. Icarus 9:498

Shimizu, M. 1969. Icarus 10:11

Sinton, W. M. 1963. The Physics of Planets, 300. Belgium: Univ. Liège

Slade, M. A., Shapiro, I. I. 1970. J. Geophys. Res. 75:3301

Slanger, T. G., Black, G. 1970. Eos 51:766

Slipher, E. C. 1962. The Photographic Story of Mars, Chap. 5. Flagstaff, Ariz: Northland Press

Smith, B. A. 1967. Science 158:114

Spinrad, H. 1966. Ap. J. 145:953

Spinrad, H., Field, G. B., Hodge, P. W. 1965. Ap.J. 141:1155

Spinrad, H., Shawl, S. J. 1966. Ap. J. 146:328

Spitzer, L. 1952. The Atmospheres of the Earth and Planets, ed. G. P. Kuiper, 211. Chicago: Univ, Chicago Press. 2nd ed.

Stewart, R. W. 1968. J. Atm. Sci. 25:578

Stewart, R. W., Hogan, J. S. 1969a. J. Alm. Sci. 26:330

Stewart, R. W., Hogan, J. S. 1969b. Science $165: 386$ 
Stone, P. H. 1968. J. Atm. Sci. $25: 644$

Thompson, R. 1970, J, Atm. Sci, 27:1107

Vinogradov, A. P., Surkov, U. A., Florensky, C. P. 1968. J. Atm. Sci. 25:535

Walker, J. C. G., Turekian, K. K., Hunten, D. M. 1970. J. Geophys. Res. 75: 3558

Wallace, L. 1969. J. Geophys. Res. 74:115

Weller, C. S., Biondi, M. A. 1967. Phys. Rev. Lett. 19:59

Westphal, J. A. 1966. J. Geophys. Res.
$71: 2693$

Whitten, R. C, 1970. J, Geophys, Res. 75: 3707

Wood, A. T. Jr.; Wattson, R. B., Pollack, J. B. 1968. Science 162:114

Young, L. D. G. 1969. Icarus 11:386

Young, L. D. G. 1970. To be published, Icarus

Young, L. D. G., Schorn, R. A., Smith, H. 1970. Icarus 13:74 


\section{CONTENTS}

Meteorites and the Early Solar System, Edward Anders . . . 1

Dwarf Galaxies, Paul W. Hodge . . . . . . . . . . 35

INFRAREd SoURCES of RAdiation, Gerry Neugebauer, Eric Becklin, and A. R. Hyland . . . . . . . . . . . . . . 67

The Nearby Stars, Peter van de Kamp . . . . . . . . . 103

Central Stars of Planetary Nebulae, E. E. Salpeter . • . . 127

The Atmospheres of Mars and Venus, Andrew $P$. Ingersoll and

Conway B. Leovy . . . . . . . . . . . . . . . 147

Evolutionary Processes in Close Binary Systems, B. Paczynski . 183

Ultraviolet Studies of the Solar Atmosphere, Robert W. Noyes . 209

The Formation of Spectral Lines, D. G. Hummer and G. Rybicki 237

Filled-Aperture Antennas for Radio Astronomy, J. W. Findlay . 271

Physical Conditions and Chemical Constitution of Dark Clouds, Carl Heiles . . . . . . . . . . . . . . . . . 293

Convection in Stars: I. Basic Boussinesq Convection, E. $A$. Spiegel . . . . . . . . . . . . . . . . . 323

Recent Developments in the Theory of Degenerate Dwarfs, Jeremiah P. Ostriker . . . . . . . . . . . . . . . . 353

Some Related Articles Appearing in Other Annual Reviews . . 367

\section{INDEXES}

AUthor INDEX . . . . . . . . . . . . . . . . . . . . 369

Subject Index . . . . . . . . . . . . . . . . . . 378

Cumulative Index of Contributing Authors, Volumes 5 to 9391

Cumulative Index of Chapter Titles, Volumes 5 to 9 . . 392 